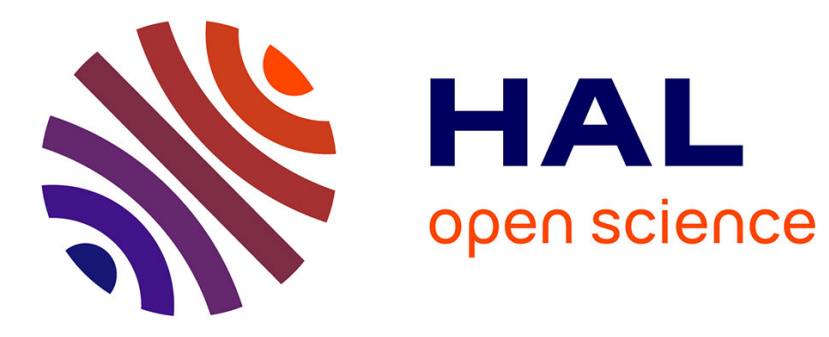

\title{
Earliest known human burial in Africa
}

María Martinón-Torres, Francesco D’errico, Elena Santos, Ana Álvaro Gallo, Noel Amano, William Archer, Simon Armitage, Juan Luis Arsuaga, José María Bermúdez de Castro, James Blinkhorn, et al.

\section{- To cite this version:}

María Martinón-Torres, Francesco D'errico, Elena Santos, Ana Álvaro Gallo, Noel Amano, et al.. Earliest known human burial in Africa. Nature, 2021, 593 (7857), pp.95-100. 10.1038/s41586-02103457-8 . hal-03345341

\section{HAL Id: hal-03345341 \\ https://hal.science/hal-03345341}

Submitted on 8 Oct 2021

HAL is a multi-disciplinary open access archive for the deposit and dissemination of scientific research documents, whether they are published or not. The documents may come from teaching and research institutions in France or abroad, or from public or private research centers.
L'archive ouverte pluridisciplinaire HAL, est destinée au dépôt et à la diffusion de documents scientifiques de niveau recherche, publiés ou non, émanant des établissements d'enseignement et de recherche français ou étrangers, des laboratoires publics ou privés. 


\section{Earliest known human burial in Africa}

María Martinón-Torres ${ }^{1,2}$, Francesco d'Errico ${ }^{3,4}$, Elena Santos ${ }^{5,6}$, Ana Álvaro Gallo ${ }^{1}$, Noel Amano ${ }^{7}$, William Archer $^{8,9,10}$, Simon J. Armitage ${ }^{11,4}$, Juan Luis Arsuaga ${ }^{5,12}$, José María Bermúdez de Castro ${ }^{1,2}$, James Blinkhorn ${ }^{7,11,13}$, Alison Crowther ${ }^{7,14}$, Katerina Douka ${ }^{7,15}$, Stéphan Dubernet ${ }^{16}$, Patrick Faulkner ${ }^{7,17}$, Pilar Fernández-Colón ${ }^{1}$, Nikos Kourampas $^{18,19}$, Jorge González García ${ }^{20}$, David Larreina ${ }^{1}$, François-Xavier Le Bourdonnec ${ }^{16}$, George MacLeod ${ }^{19}$, Laura Martín-Francés $^{1,2}$, Diyendo Massilani ${ }^{21}$, Julio Mercader ${ }^{7,22}$, Jennifer M. Miller ${ }^{7}$, Emmanuel Ndiema ${ }^{7,23}$, Belén Notario $^{1}$, Africa Pitarch Martî3,24, Mary E. Prendergast ${ }^{25}$, Alain Queffelec ${ }^{3}$, Solange Rigaud ${ }^{3}$, Patrick Roberts ${ }^{7,14}$, Mohammad Javad Shoaee ${ }^{7}$, Ceri Shipton ${ }^{26,27}$, Ian Simpson ${ }^{18}$, Nicole Boivin ${ }^{7,14,22,28}$ \& Michael D. Petraglia ${ }^{7,14,29,30}$

${ }^{1}$ CENIEH (National Research Center on Human Evolution), Burgos, Spain.

${ }^{2}$ Anthropology Department, University College London, London, UK.

${ }^{3}$ UMR 5199 CNRS De la Préhistoire à l'Actuel: Culture, Environnement, et Anthropologie (PACEA), Université Bordeaux, Talence, France.

${ }^{4}$ SFF Centre for Early Sapiens Behaviour (SapienCE), University of Bergen, Bergen, Norway.

${ }^{5}$ Centro Mixto UCM-ISCIII de Evolución y Comportamiento Humanos, Instituto de Salud Carlos III, Madrid, Spain.

${ }^{6}$ Cátedra de Otoacústica Evolutiva y Paleoantropología (HM Hospitales - Universidad de Alcalá), Departamento de Ciencias de la Vida, Universidad de Alcalá, Alcalá de Henares, Spain.

${ }^{7}$ Department of Archaeology, Max Planck Institute for the Science of Human History, Jena, Germany.

${ }^{8}$ Department of Archaeology and Anthropology, National Museum, Bloemfontein, South Africa.

${ }^{9}$ Department of Archaeology, University of Cape Town, Cape Town, South Africa.

${ }^{10}$ Department of Human Evolution, Max Planck Institute for Evolutionary Anthropology, Leipzig, Germany.

${ }^{11}$ Department of Geography, Royal Holloway, University of London, Egham, UK.

${ }^{12}$ Departamento de Paleontología, Facultad de Ciencias Geológicas, Universidad Complutense de Madrid, Madrid, Spain.

${ }^{13}$ Pan-African Evolution Research Group, Max Planck Institute for the Science of Human History, Jena, Germany.

${ }^{14}$ School of Social Science, The University of Queensland, Brisbane, Queensland, Australia.

${ }^{15}$ Research Laboratory for Archaeology and the History of Art, University of Oxford, Oxford, UK.

${ }^{16}$ UMR 5060 CNRS-Université Bordeaux Montaigne IRAMAT-CRP2A: Institut de recherche sur les Archéomatériaux - Centre de recherche en physique appliquée à l'archéologie, Maison de l'archéologie, Pessac, France.

${ }^{17}$ Faculty of Arts and Social Sciences, Department of Archaeology, The University of Sydney, Sydney, New South Wales, Australia.

${ }^{18}$ Centre for Open Learning, University of Edinburgh, Edinburgh, UK.

${ }^{19}$ Biological and Environmental Sciences, University of Stirling, Stirling, UK.

${ }^{20} 3 \mathrm{D}$ Applications Engineer and Heritage Specialist Digital Heritage and Humanities Collections, University of South Florida, Tampa, FL, USA.

${ }^{21}$ Department of Evolutionary Genetics, Max Planck Institute for Evolutionary Anthropology, Leipzig, Germany.

${ }^{22}$ Department of Anthropology and Archaeology, University of Calgary, Calgary, Alberta, Canada.

${ }^{23}$ National Museums of Kenya, Department of Earth Sciences, Nairobi, Kenya.

${ }^{24}$ Seminari d'Estudis i Recerques Prehistòriques (SERP), Facultat de Geografia i Història, Departament d'Història i Arqueologia, Universitat de Barcelona, Barcelona, Spain.

${ }^{25}$ Department of Anthropology, Rice University, Houston, TX, USA.

${ }^{26}$ Institute of Archaeology, University College London, London, UK.

${ }^{27}$ Centre of Excellence for Australian Biodiversity and Heritage, The Australian National University, Canberra, Australian Capital Territory, Australia.

${ }^{28}$ Department of Anthropology, National Museum of Natural History, Smithsonian Institution, Washington, DC, USA.

${ }^{29}$ Human Origins Program, National Museum of Natural History, Smithsonian Institution, Washington, DC, USA.

${ }^{30}$ Australian Research Centre for Human Evolution (ARCHE), Griffith University, Brisbane, Queensland, Australia. 


\section{Abstract}

The origin and evolution of hominin mortuary practices are topics of intense interest and debate ${ }^{1-3}$. Human burials dated to the Middle Stone Age (MSA) are exceedingly rare in Africa and unknown in East Africa ${ }^{1-6}$. Here we describe the partial skeleton of a roughly 2.5 - to 3.0-year-old child dating to $78.3 \pm 4.1$ thousand years ago, which was recovered in the MSA layers of Panga ya Saidi (PYS), a cave site in the tropical upland coast of Kenya $^{7,8}$. Recent excavations have revealed a pit feature containing a child in a flexed position. Geochemical, granulometric and micromorphological analyses of the burial pit content and encasing archaeological layers indicate that the pit was deliberately excavated. Taphonomical evidence, such as the strict articulation or good anatomical association of the skeletal elements and histological evidence of putrefaction, support the in-place decomposition of the fresh body. The presence of little or no displacement of the unstable joints during decomposition points to an interment in a filled space (grave earth), making the PYS finding the oldest known human burial in Africa. The morphological assessment of the partial skeleton is consistent with its assignment to Homo sapiens, although the preservation of some primitive features in the dentition supports increasing evidence for non-gradual assembly of modern traits during the emergence of our species. The PYS burial sheds light on how MSA populations interacted with the dead.

\section{Introduction}

Increasing scrutiny is being placed on the origin and biological and cultural evolution of our species in Africa ${ }^{1-3}$. Mortuary practices are an important component of our evolution ${ }^{46}$. Formal burials, defined as the interment of a dead body in an excavated grave, may have been preceded by more elusive practices in the genus Homo. Testing this scenario is made difficult, particularly in Africa, by the scarcity of sites with clear and well-dated evidence for the treatment of dead bodies.

PYS has emerged as one of the key MSA and Later Stone Age (LSA) sites in Africa, given its excellent preservation of environmental proxies ${ }^{7,8}$, its distinctive sequence of technological innovations and symbolic traits ${ }^{8,9}$, and its preservation of biomolecular information ${ }^{10,11}$. The excavated cave sequence is about $3 \mathrm{~m}$ deep and encompasses 19 layers (Fig. 1). A series of stratigraphically ordered radiocarbon and luminescence ages, when included in a Bayesian model, indicate human occupation from about 78 thousand years ago (ka) to 500 years ago ${ }^{8}$, representing most of the last five marine isotope stages. 

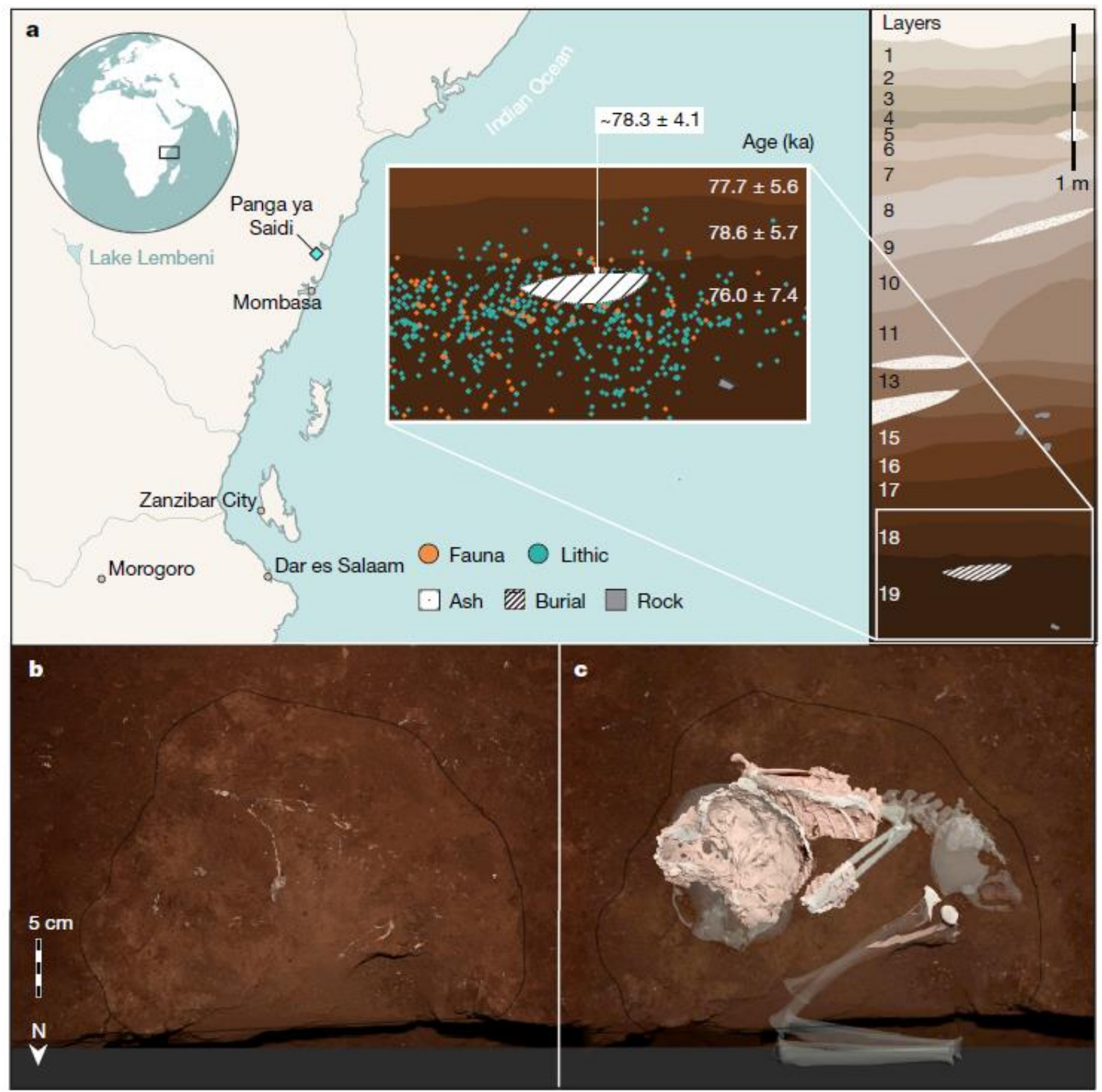

Fig. 1 | Location of PYS and stratigraphic context of burial. a, PYS is located in the uplands of Kenya's coastal plain. Right, the 19 stratigraphic layers with the burial pit at the bottom of MSA layer 18 and in layer 19. Detailed inset of burial pit shows piece-plotted objects, including MSA lithics and fauna and three associated OSL dates in layers 17-19. The Bayesian age is $78.3 \pm 4.1 \mathrm{ka}$. b, Plan view of the 2017 excavation. The black line delimits the pit feature and the change in texture from the surrounding matrix. The faint white outline of the decomposed skull, spine, femur and other severely degraded bones can be observed on the surface of the pit. c, Same view with the superimposition of the virtual reconstruction of the CT and surface scans of Mtoto. The preserved parts (solid) are superimposed over a semitransparent comparative skeleton to better depict the position of the child.

The 2013 excavations at PYS revealed a partial pit feature in profile, markedly contrasting with the gradual colour change that characterizes the entire sequence and presenting a distinct texture and colour in comparison to the surrounding matrix (Fig. 1, Supplementary Information A). A luminescence tube (OSL4) and a micromorphology sample (PYS 13_1) were placed in the feature. The micromorphology sample revealed the presence of heavily degraded bones. Excavations were expanded in 2017 to expose the top of the feature, which was positioned at the bottom of layer 
18. The plan view of the pit was subcircular, measuring $36.7 \mathrm{~cm}$ (north-south) by $39.8 \mathrm{~cm}$ (west-east) by $12.5 \mathrm{~cm}$ (depth). Limited excavation at the top of the pit indicated that the feature contained a concentration of fragile and degraded bones in association with MSA lithic artefacts (Extended Data Fig. 1, Supplementary Information B), embedded in a matrix that differed from the surrounding sediments of layer 19. The excavation surface indicated the presence of decomposed bones that were later shown to be the base of a skull and the articulated spine of a child.

Several small fragments of bone were exposed during the 2017 excavation but because they were poorly preserved, it was decided to plaster the whole feature and transport it for careful laboratory excavation. The plastered remains were first taken to the National Museums of Kenya (NMK), and then to the Conservation and Restoration laboratories at CENIEH in Burgos, Spain for mechanical and digital cleaning (Supplementary Information A).

Careful examination revealed the articulated partial skeleton of an immature human (Fig. 2). Sample OSL4, taken directly from the feature in 2013, was processed at Royal Holloway, London, resulting in a stratigraphically coherent age of $76.0 \pm 7.4 \mathrm{ka}$ (luminescence ages are presented at the $68.2 \%$ confidence interval throughout). Incorporation of this age into the Bayesian model yielded an estimated age of 78.3 $\pm 4.1 \mathrm{ka}$ for the pit infilling (Extended Data Fig. 2, Supplementary Information C). Excavation of the sediment block that encased the skeletal elements revealed the presence of lithics and fauna (Supplementary Information B, Extended Data Fig. 1, Extended Data Table 1) that were consistent with the surrounding MSA layers. Layers 17-19 produced a large MSA lithic assemblage $(n=2,180)$ that was distinct from the LSA layers above ${ }^{8}$ and consistent with other MSA assemblages in eastern Africa ${ }^{12}$. Screening of the sediment and skeletal elements for ancient DNA proved inconclusive (Supplementary Information D).

\section{Materials and Methods}

\section{Luminescence dating}

A suite of seven quartz single-grain OSL ages for PYS were previously published, including a detailed description of the luminescence measurement and data analysis techniques used (supplementary note 3 in Shipton et al. ${ }^{8}$ ). These data were stratigraphically consistent, and were combined with a number of radiocarbon ages to construct an age model using Bayesian software (OxCal 4.4.2). The resulting chronology was internally consistent, but analysis of the singlegrain data from samples located towards the base of the sedimentary sequence indicated that a high proportion of the grains were close to 'saturation'; that is, they had received a natural radiation dose that was sufficiently close to the saturation dose to preclude the calculation of an accurate equivalent does $\left(D_{\mathrm{e}}\right)$ value. Both the method used to identify saturated quartz grains ${ }^{46}$, and the presence of a high proportion of such grains ${ }^{47}$, have the potential to cause the age to be underestimated. Consequently, in the present study, single grains of potassium feldspars (K-feldspar) from five samples from PYS were measured using a post-infrared, infrared-stimulated luminescence (pIRIR) measurement protocol $^{48}$. These measurements were performed on the two deepest (oldest) previously published samples (PYS13OSL3 and OSL5), a new sample from the burial (PYS13-OSL4), and two younger samples (PYS13-OSL11 and OSL17). As K-feldspar is known to saturate at much higher doses than quartz, this approach allows the accuracy of the 
older published ages to be tested. Measurement and data analysis procedures are described in Supplementary Information C.

The K-feldspar measurements, combined with reanalysis of the quartz data, indicate that the published OSL ages ${ }^{8}$ for layers 17 and 18 are underestimates, but those for younger layers are accurate. Ages deemed to be accurate were incorporated into a new age model using Bayesian software (OxCal 4.4.2). The K-feldspar age for the PYS13-OSL4, the sample within the burial, is consistent with those for the surrounding sediments (PYS13-OSL3 and OSL5). If the burial pit had been dug into much older sediments and then infilled using those sediments, some grains would probably have had their luminescence signal reset during the process. This might be expected to yield a younger age for the burial infill than the surrounding sediments, which is not the case for the K-feldspar ages. The quartz ages for these samples, although believed to be underestimates, are also indistinguishable. Also, the overdispersion of the quartz data are similar for samples PYS13-OSL3-5. This suggests that the burial occurred sufficiently shortly after deposition of layers 17 and 18 that bleaching of grains during the excavation and infilling processes did not increase the scatter of equivalent doses. The similarity in K-feldspar ages and quartz overdispersion between samples PYS13-OSL3-5 does not unequivocally demonstrate that the burial infill is contemporaneous with layers 17 and 18, because if the pit was backfilled with spoil this might have occurred under subdued light conditions, leading to poor luminescence signal resetting. Also, given the approximately $7-10 \%$ uncertainties on individual K-feldspar ages, archaeologically important differences in age could go unnoticed. Nonetheless, the absence of a discrepancy between the ages and overdispersion of the burial infill and surrounding sediments suggests that the burial is contemporaneous with layers 17 and 18, at least at the temporal resolution achievable using luminescence techniques.

\section{Bayesian modelling and age of the PYS burial}

Bayesian modelling enables the relative stratigraphic information recorded during excavation to be formally incorporated into posterior age estimates derived from chronometric data expressed as probability distributions (in this case, calibrated radiocarbon and luminescence probability distributions) and 'prior' information (that is, observations on the data we collect). In archaeology, this is often the stratigraphic and other relative information. Hence 'posterior' data is a probability function that reflects the level of confidence associated with the values of the unknown parameters, in this case chronometric measurements, after the observation of the prior information. Details about the data and structure of the comprehensive model for the dating of the PYS sequence have previously been described ${ }^{7}$.

Here we updated the model, using recalculated OSL ages for layers 9-15, replacing OSL ages for layers 17 and 18 with new pIRIR ages, and adding the new pIRIR age obtained for the burial infill (OSL4). The standard errors associated with the luminescence ages include both random and systematic uncertainties. This updated model was run using OxCal 4.4. $2^{49}$, and the code is shown in Supplementary Information C. By inserting a 'Date' command into the OxCal structure we allow the model to find the best fit for the age of the burial on the basis of all luminescence ages obtained for relevant layers 17 and 18 (Supplementary Table C4). Because of uncertainties in the bleaching history of sediment grains

deriving from disturbed contexts, such as a burial, we do not tie the 'Date' command to OSL4; instead, we treat the burial infill sediment as another independent age for layer 18 . 
Given that layers 17 and 18 are statistically indistinguishable from each other and from OSL4, we may assume that both layers are quasi-contemporaneous, at least at the precision offered by the luminescence methods, for the studied period. The new model is shown in Extended Data Fig. 2.

\section{Screening for ancient DNA}

DNA extraction and library preparation. We screened eight undiagnosed skeletal fragments and twelve sediment samples associated with the PYS burial pit for ancient DNA (Supplementary Table D1). DNA was extracted from about $50 \mathrm{mg}$ of bone or sediment using a silica-based method developed for the retrieval of short DNA molecules ${ }^{50}$ on an automated liquid handling platform ${ }^{51}$. Fifteen per cent of each extract was converted into a single-stranded DNA library ${ }^{52}$, and barcoded with a pair of unique indices ${ }^{53}$, following the modifications described in Korlević et al. ${ }^{54}$. The number of DNA molecules incorporated into each library was assessed by quantitative PCR as previously described ${ }^{55}$. Extraction and library negative controls were carried through all steps of the experiments. Libraries were pooled and shotgun sequenced on a HiSeq platform (Illumina).

Mitochondrial capture and sequencing. One microgram of each amplified DNA library was enriched either for mammalian mitochondrial DNA (mtDNA) using a probe set of $242 \operatorname{taxa}^{56}$ or for human mtDNA with a probe set covering the full human mitochondrial genome ${ }^{57,58}$. The enriched libraries were pooled in two sets according to the capture probe used and sequenced on a MiSeq platform (Illumina).

Sequence processing and mapping. The reads obtained from the sequencing of the mtDNA-enriched libraries were trimmed to remove adaptor sequences, and overlapping paired-end reads were merged using leeHom ${ }^{59}$. Sequences from the mammalian mtDNA-enriched libraries were aligned to a non-redundant database of 796 mammalian mitochondrial genomes from the NCBI Reference Sequence database (RefSeq) using nucleotide BLAST (BlastN) ${ }^{60}$ with default parameters. Sequences were then assigned to different taxa using MEGAN ${ }^{61}$ and each ancient taxon was deemed present in the dataset if it met previously published criteria ${ }^{62}$. The sequences from the human mtDNA-enriched libraries were aligned to the revised Cambridge Reference mitochondrial genome (rCRS, NC_0120920) using the Burrows-Wheeler aligner ${ }^{63}$ with optimized parameters for ancient DNA «-n $0.01-\mathrm{o} 2-1$ 16500» ${ }^{64}$. Aligned sequences shorter than 35 bases with a mapping quality lower than 25 were filtered out. PCR duplicates were removed by merging sequences with identical alignment start and end coordinates using bam-rmdup (https://github.com/mpieva/ biohazard$\underline{\text { tools). }}$.

\section{Virtual reconstruction}

The PYS remains were recovered encased in a block and had to be manually and mechanically prepared for study. Given the delicate preservation and infantile age of the specimen, a microCT scan was performed to extract digital 3D models of the teeth and bones, which were still embedded within the sediment. Because of the delicate state of preservation and the need to preserve the information regarding the position of the body, we decided on a combination of mechanical and virtual isolation of the skeleton. However, the low density of the bones prevented proper virtual 
isolation of the elements, and it was necessary to carefully isolate the cranial from the postcranial elements (Supplementary Information A) and to combine microCT and surface scanners to reconstruct the original position of the child inside the block. The microCT scans were performed at the Laboratory of Microscopy of the Centro Nacional de Investigacion sobre la Evolucion Humana-Unique Scientific \& Technical Infrastuctures (CENIEH-ICTS, Burgos) with a Phoenix v|tome|x s (GE Measurement \& Control). First, the entire block was scanned at $140 \mathrm{kV}$ and $400 \mu \mathrm{A}$, with a $0.2-\mathrm{mm} \mathrm{Cu}$ filter and an integration time of $333 \mathrm{~ms}$, which resulted in an isometric voxel size of $0.1227 \mathrm{~mm}$. As the remains were carefully manually cleaned, we performed a microCT of the block containing the cranial remains at $200 \mathrm{kV}$ and $400 \mu \mathrm{A}$, with the same filter and integration time, resulting in an isometric voxel size of $0.0769 \mathrm{~mm}$, and another scan of the block containing the postcranial elements at $140 \mathrm{kV}$ and $250 \mu \mathrm{A}$, with the same filter and integration time, resulting in an isometric voxel size of $0.0479 \mathrm{~mm}$. Each isolated tooth and each smaller block that resulted from the mechanical excavation were also microCT scanned. Additionally, surface scans were performed with a hand scanner (Artec Space Spider) under conditions of artificial light for each excavated element, and the scans were processed using Artec Studio 11 software to create surface models. Digital cleaning and segmentation were performed with Mimics 18.0 (Materialise, Be) and Avizo 7.0 (Visualization Sciences Group, 2012) using a combination of automatic and manual segmentation, to generate STL files of all PYS remains. Digital renderings of the specimen in several views were done with Avizo, Mimics and MeshLab. With the digital renders, it was possible to identify several anatomical elements, such as the first vertebra in anatomical connection. The identification of two teeth and several shells in the first microCT of the main block was useful to provide reference landmarks to later orient the microCT of the skull and the CT and surface scans of the thorax in their original position. Furthermore, and to understand the position of the child within the block, the skull of a Homo sapiens child in a similar stage of development was microCT scanned and virtually reconstructed. Using Mimics and MeshLab software, both PYS and Homo sapiens crania were superimposed with the registration and align tool. A best-fit was made to reference them in the best position and to see which parts were deformed or displaced. Furthermore, both crania were placed again in the burial pit using as a reference the two teeth identified in the first microCT scan of the main block. In addition, a comparative human skeleton of H. sapiens of a similar age was scanned using the same surface scanner to obtain digital models of all the long bones, hips and ribs, to help reconstruct the original position of the child inside the burial. Using Mimics software, all the models were scaled to obtain a length similar to that of a 2.5-3-year-old child (following Scheuer and Black ${ }^{65}$ ). To align the comparative skeleton with the PYS remains, the STL models of the vertebral column, ribs, clavicle, scapula and humerus were aligned using both the CT of the entire block and the CT of the PYS vertebral column.

Once all the remains and comparative models had been aligned, we used 3ds Max 2020 (Autodesk), combing the topopgraphic information available from the field, photographs of the excavation plan, and all STL and OBJ models of both Mtoto and the comparative skeleton, to produce the closest reconstruction of the original position of the child when it was found at the site. Each anatomical element was reoriented following the topographic field information and the orthophotos of the site. When all the remains had been located in space, we proceeded to create textures, shadows and lights, to visualize the preserved skeletal elements and to integrate them into their original positions in the comparative 
skeleton. Some renderings have been made using the semi-transparent comparative skeleton, to understand and visualize the position of the PYS remains in the burial, and to understand its anatomical connections.

\section{Thin-section micromorphology and bone microscopy}

A micromorphology sample collected in a $6 \times 10-\mathrm{cm}$ polyurethane box at the end of the 2013 field season (PYS 2013_M1:19/18) intercepted soft, degraded bone. This sample was not processed for micromorphological analysis: it was stored until 2019, when it became apparent that it may have contained parts of Mtoto's skeleton (probably fragments of lower limbs and ribs). The box was then excavated at CENIEH (Burgos). In the course of this excavation, centimetresized bone fragments and lumps of the sediment matrix were collected for microscopic investigation. Bone and sediment were air-dried and impregnated with polyester resin under desiccation vacuum. One uncovered petrographic thin section (30- $\mu \mathrm{m}$ thick) was produced from the impregnated block. The section was examined under a polarizing microscope $(\times 10$ to $\times 400$ magnification) with plane polarized (PPL), cross-polarized (XPL) and oblique incident light (OIL). Our description of the sediment features follows Bullock et $\mathrm{al}^{66}$, Stoops ${ }^{67}$ and Stoops et al. ${ }^{68}$. Estimates and measurements of sediment inclusions and histological attributes of the bone fragments were made with the aid of standard semiquantitative estimation charts and the analySIS pro5 image analysis software. The degree of diagenetic alteration of bone was estimated mainly through optical microscopy, using the General Histology (GH) index ${ }^{69}$ - an estimate of microstructural alteration similar to the more commonly used Oxford Histology index ${ }^{70,71}(\mathrm{OHI})$, but taking into account other types of structural and compositional alteration (generalized destruction, staining, accumulation of authigenic deposits and fissuring) besides bioerosion. Where identifiable, microscopic bioerosion ('microscopical focal destruction', MFD ${ }^{72}$ ) was recorded following the typology proposed by Hackett ${ }^{72}$ and Jans ${ }^{73}$. Scanning electron microscopy coupled with energy dispersive X-ray spectroscopy (SEM-EDS) analysis (on a Zeiss EVO-MA15, with an Oxford Instruments InCA Max 80 mm EDS) was carried out on the polished, uncoated thin section, to observe bone microstructure at higher magnifications and determine the elemental composition of selected features. Low-vacuum conditions were used (60 Pa) to prevent charging of the sample surface; strict operating conditions of $50 \mu \mathrm{A}$ filament current, $2.525 \mathrm{~A}$ gun current, $20 \mathrm{kV}$ accelerating voltage, and an 8.5-mm working distance to achieve an acquisition rate of $15 \mathrm{kcps}$ were applied to standardize the analyses. A polished Co standard was analysed to adjust for beam current drift, and a polished dolomite standard was used to confirm the accuracy of the calculated absolute element concentrations. Navigation on the sample was aided by section scans. Data are reported as non-normalized percentage weights.

\section{Dental analysis}

Comparative metrical and morphological study of teeth. The evaluation of morphological features was made on the original fossils and the virtual images obtained by microtomography. The descriptive terminology used in this report derives from the following sources: Carlsen $^{74}$, Tobias $^{75}$, Turner et al. ${ }^{76}$, Scott and Turner ${ }^{77}$, Martinón-Torres et al. ${ }^{78}$, Martinón-Torres et al. ${ }^{79}$, Martínez de Pinillos et al. ${ }^{80}$, and table 4 in Martinón-Torres et al. ${ }^{81}$, which includes a 
modified version of the Arizona State University Dental Anthropological System (ASUDAS) of scoring. Occlusal wear was recorded following Molnar ${ }^{82}$. The comparison was focused in the Late Pleistocene samples, H. sapiens and $H$. neanderthalensis, although several samples from Middle to Late Pleistocene Africa were included to assess the variability of the African fossil record. The mesiodistal (MD) and buccolingual (BL) dimensions of the PYS child were measured by J.M.B.d.C. to the nearest $0.1 \mathrm{~mm}$, following the methods of Flechier, Lefêvre, and Verdéne ${ }^{83}$. Apart from the $\mathrm{MD}$ and the $\mathrm{BL}$, we also calculated the computed crown area (CCA: $\mathrm{MD} \times \mathrm{BL})$ and the measured crown area $(\mathrm{CI}$ : $[B L / M D] \times 100)$. In addition, the cusp areas of the M1s were measured following Bermúdez de Castro et al. ${ }^{84}$ and using the criteria outlined by Bailey ${ }^{85}$. The areas were measured three times and the average of the three values was used. The total crown base area (TCBA) was calculated as the sum of all the individual cusp areas. The PYS values were compared against a large hominin sample of $H$. sapiens, $H$. neanderthalensis and some relevant Middle to Late Pleistocene fossils from Africa.

Enamel thickness. Virtual sectioning of the molars was performed following the protocol described by Olejniczak and colleagues ${ }^{86}$. The mCT image stack was imported into Amira (6.3.0, FEI) and rotated into anatomical position. Then, the tip of three dentine horns (protoconid, metaconid and hypoconid in the mandibular molars and protocone, paracone and hypocone in the maxillary molars) were identified and the image stack was adjusted to intersect these three points of interest. A new plane perpendicular to the plane containing the three dentine horns was rotated to pass through the mesial dentine horns (protoconid and metaconid in the mandibular molars and protocone and paracone in the maxillary molars). We assessed enamel thickness from virtual 2D mesial cross-section planes in each PYS molar as described by Martin ${ }^{87}$ using Amira (6.2, FEI) and ImageJ (1.51, NIH). In each mesial plane, we measured the enamel (c) and dentine cap ( $b$, including the pulp) areas (in $\left.\mathrm{mm}^{2}\right)$, adding up to the total crown area $\left(a\right.$, in $\left.\mathrm{mm}^{2}\right)$, and the EDJ length $(d$, in $\mathrm{mm})$. We calculated the average enamel thickness $(\mathrm{AET}=c / d)$, the relative enamel thickness $($ RET $=100$ $\left.\times \operatorname{AET} /\left(b^{0.5}\right)\right)$ and the percentage of dentine and pulp in the molar crown $(b / a=100 \times b / a$, in $\%)$. We assessed volume enamel thickness of the molar caps in the complete sample from PYS. Using Amira (6.3.0, FEI) we performed segmentation of the dental tissues (enamel, dentine and pulp). We used the semiautomatic tool, threshold-based segmentation, and manual corrections. We used the protocol of Olejniczak et al. ${ }^{86}$ to define the cervical plane- that is, the plane halfway between the most apical continuous ring of enamel and the plane containing the last hint of enamel. The following variables were measured and/or calculated: volume of the enamel $\left(V_{\mathrm{e}}\right.$ in $\left.\mathrm{mm}^{3}\right)$; volume of the coronal dentine including the pulp enclosed in the crown $\left(V_{\text {cdp }}\right.$ in $\left.\mathrm{mm}^{3}\right)$; total volume of the crown, including the enamel, dentine and pulp $\left(V_{\mathrm{c}}\right.$ in $\left.\mathrm{mm}^{3}\right)$; surface of the EDJ (SEDJ in $\left.\mathrm{mm}^{2}\right)$; percentage of dentine and pulp in the total crown volume

$\left(V_{\text {cdp }} / V_{\mathrm{c}}=100 \times V_{\text {cdp }} / V_{\mathrm{c}}\right.$ in $\left.\%\right) ; 3 \mathrm{D}$ average enamel thickness $\left(3 \mathrm{D} \mathrm{AET}=V_{\mathrm{e}} / \mathrm{SEDJ}\right.$ in $\left.\mathrm{mm}\right)$ and 3D relative enamel thickness $(3 \mathrm{D}$ RET $=100 \times 3 \mathrm{D}$ AET/

$\left(V_{\mathrm{cdp}}{ }^{1 / 3}\right)$, a scale-free measurement $)^{86,88}$. To extract the largest amount of information from the PYS specimens and the comparative samples, including the occlusal worn molars, we assessed lateral (non-occlusal) enamel thickness in the complete sample. In Amira (6.3.0, FEI) we defined the occlusal basin plane, a plane parallel to the cervical plane and tangential to the lowest enamel point of the occlusal basin. All material above the occlusal basin plane was removed and only the enamel, dentine and pulp between these two planes were measured ${ }^{89,90}$. The following variables were 
measured and/or calculated: lateral volume of the enamel $\left(\mathrm{LV}_{\mathrm{e}}\right.$ in $\left.\mathrm{mm}^{3}\right)$; lateral volume of the coronal dentine including the pulp enclosed in the crown $\left(\mathrm{LV}_{\text {cdp }}\right.$ in $\left.\mathrm{mm}^{3}\right)$; total lateral volume of the crown, including the lateral enamel, dentine and pulp $\left(\mathrm{LV}_{\mathrm{c}}\right.$ in $\left.\mathrm{mm}^{3}\right)$; lateral surface of the EDJ (LSEDJ in $\left.\mathrm{mm}^{2}\right)$; percentage of dentine and pulp in the lateral crown volume $\left(\mathrm{LV}_{\mathrm{cdp}} / \mathrm{LV}_{\mathrm{c}}=100 \times \mathrm{LV}_{\mathrm{cdp}} / \mathrm{LV}_{\mathrm{c}}\right.$ in \%); 3D average enamel thickness (3D LAET $=\mathrm{LV}_{\mathrm{e}} / \mathrm{LSEDJ}$ in mm) and 3D lateral relative enamel thickness $\left(3 \mathrm{D} \mathrm{LRET}=100 \times 3 \mathrm{D} \mathrm{LAET} /\left(\mathrm{LV}_{\mathrm{cdp}}{ }^{1 / 3}\right) \text {, a scale-free measurement }\right)^{91}$. The results of the $2 \mathrm{D}$ and $3 \mathrm{D}$ measurements in PYS specimens were compared with two populations: Neanderthals and modern humans. Adjusted Z-scores ${ }^{92,93}$ of the three variables accounting for tissue proportions (percentage of dentine, AET and RET) were computed to compare 2D and 3D values of the PYS specimens to the means and standard deviations of the Neanderthal and modern human groups. This statistical method allows the comparison of unbalanced samples by using Student's inverse $t$-distribution. In these $Z$-scores, the -1.0 to +1.0 interval comprises $95 \%$ of the variation in the reference sample. In addition, standard box and whisker plots were computed to represent three sets of variables of crown volume and lateral volume (including 3D $V_{\text {cdp }} / V_{\mathrm{c}}, 3 \mathrm{D}$ AET, 3D RET and 3D $\mathrm{LV}_{\mathrm{cdp}} / V_{\mathrm{c}}, 3 \mathrm{D}$ LAET, 3D LRET) in the PYS sample and the complete comparative specimens and/or groups.

Tissue distribution (cartographic maps). To visualize the topographic distribution of enamel thickness in PYS specimens, 3D chromatic maps were generated in Amira (6.3.0, FEI). The defined chromatic scale is from thinnest (blue) to thickest (red) ${ }^{94,95}$. For comparative purposes, we generated chromatic maps of a selected sample of specimens, including: Neanderthals from Roc de Marsal (lower and upper deciduous m2), La Quina (upper permanent M1) and Abri Suard (lower permanent M1); Fossil H. sapiens from La Madaleine (lower deciduous m2), Qafzeh (upper deciduous $\mathrm{m} 2$ and upper and lower permanent M1); and modern humans of European origin (upper and lower deciduous $\mathrm{m} 2$, and upper and lower permanent M1).

Geometric morphometric analysis of the EDJ. We performed geometric morphometric analysis of the EDJ morphology on the virtual surfaces of PYS specimens and a comparative sample that included Neanderthals, fossil $H$. sapiens and modern humans (Supplementary Table F4). We reconstructed the slightly worn dentine horns of the comparative sample in Geomagic Studio (version 2012; https://www. geomagic.com) with the fill-holes tool. When necessary, we mirrored the comparative specimens according to the PYS molar type. Using the landmark tool in Amira, we placed one landmark on the dentine horn tip of each main cusp (protocone, paracone, metacone and hypocone on maxillary molars, and protoconid, metaconid, hypoconid, entoconid and hypocunulid on mandibular molars). Next, we placed a set of semilandmarks (96 and 95 points in maxillary and mandibular molars, respectively) along the marginal crests. In each molar, configuration segments were saved independently. Using the package R, we generated a document containing the coordinate configuration for each molar type. Then, using R package, we performed weighted betweengroup principal component analysis (bgPCA) on the basis of the Procrustes and deformation-based shape residuals ${ }^{96}$. Finally, we tested for allometry on the landmark-based analyses using the coefficient of determination $\left(R^{2}\right)$ of a multiple regression ${ }^{97}$, in which the explicative variable is the centroid size and the dependent variables are the bgPC scores ${ }^{98}$. 
Faunal analysis

Zooarchaeology. Two separate zooarchaeological studies were conducted: N.A. analysed remains from burial fill at the Max Planck Institute for the Science of Human History in Jena, and M.E.P. analysed remains from trenches 3 and 4 at the National Museums of Kenya in Nairobi. Access to comparative skeletal material for eastern Africa was distinct in each study, and analytical protocols differed somewhat.

Fauna, burial fill. For the burial fill (context 809 in trench 8), all bone fragments were sorted, counted and measured (length, width and thickness) using a digital caliper (Mitutoyo 500-463), regardless of identifiability. The specimens were recorded in detail using codes following a zonation system that allowed the description of fragmentation patterns. All identified fragments were examined for bone surface modifications under a Nikon C-PCN stereomicroscope.

Fauna, trenches 3 and 4. For trenches 3 and 4, faunal remains are reported from the following layers and contexts: layer 17 (contexts 316X, 317Y-Z, 420B-F), layer 18 (422A-C), layer 19 (423A-D). These remains were weighed and sorted into those identifiable at least to a minimal level (for example, mammal limb bone), and those not easily identifiable at any level. For each identified specimen, recorded variables include taxon, element, portion, side, weathering, breakage, and bone surface modifications. Cortical surfaces of all identified specimens were examined with a $20 \times$ hand lens under strong oblique light.

\section{Sediment analysis}

Two sets of samples were analysed in the framework of this study. The first set comprised sediment samples from archaeological layers and the burial pit. The second set included reddish micro-agglomerates associated with the child's remains.

Sediment analysis from archaeological layers and the burial pit. Two groups of sediment samples were analysed. The first group comprises twenty-four samples of sediment collected during the excavation of trenches 3 and 8 in 2017 (PYS-2017-200127 to PYS-2017-200153). They come from layers 17, 18 and 19, and were collected at 2-cm depth intervals. They do not include sediment from the burial (Supplementary Table G1).

The second group comprises five sediment samples collected close to the human remains (Supplementary Table G2). Three samples, reddish-brown in colour, were retrieved close to the maxilla, the face, and inside the cranial vault. The other two, brownish in colour, were collected close to the occipital bone and the postcranial perimeter. These five samples were retrieved during the excavation of the skeleton at the CENIEH Conservation and Restoration Laboratory.

The sediment samples were studied at the UMR 5199 PACEA and UMR 5060 IRAMAT/CRP2A laboratories in Bordeaux. The samples were examined and photographed with a motorized Leica Z6 APOA microscope equipped with a DFC420 digital camera. Uploaded images were treated with Leica Application Suite equipped with the Multifocus module. Samples were then prepared for grain-size analysis with a Horiba LA-950 laser particle size analyser. The sample pre-treatment included suspension in sodium hexametaphosphate $(5 \mathrm{~g} / \mathrm{l})$ and hydrogen peroxide $(35 \%)$ at room temperature for $12 \mathrm{~h}$. The resulting compound was subjected to $60 \mathrm{~s}$ ultrasonification to achieve optimal dispersion. 
The Mie solution to Maxwell's equation provided the basis for calculating the particle size ${ }^{99,100}$, using a refractive index of 1.333 for water and $1.55-0.01 i$ for the particles. The grain-size distributions expressed in $\phi$ units were decomposed in different Gaussian populations (parametric curve fitting method) using the mixdist $\mathrm{R}$ package ${ }^{101}$ to identify the main modes and their relative proportions. The limits used for grain-size classes are as follows: <7 $\mu \mathrm{m}$ (clays), 7-63 $\mu \mathrm{m}$ (silts) and 63-2,000 $\mu \mathrm{m}$ (sands). These limits were based on studies showing that the number of clay particles measured by laser diffraction is usually underestimated (for example, Konert and Vandenberghe ${ }^{102}$ ).

Elemental analysis was carried out using a hand-held SPECTRO xSORT energy dispersive X-ray fluorescence (EDXRF) spectrometer from Ametek. This instrument is equipped with a silicon drift detector (SDD), a low power W $\mathrm{X}$-ray tube with an excitation source of $40 \mathrm{kV}$, and an X-ray beam of $8 \mathrm{~mm}$. Spectrum acquisition times were set to 300 s. Measurements were performed with a constant working distance by using a positioning device consisting of a lead receptacle to which the spectrometer was fixed. Samples were ground and homogenized with an agate mortar and then placed into a plastic cup covered with a Prolene thin film. Three measurements were taken on each sample. Element contents were calculated as the average of these acquisitions. To precisely quantify the elemental composition of the samples, we applied a dedicated calibration for sediment samples (see Sitzia et al. ${ }^{103}$ for details). This calibration allows quantification of $\mathrm{Si}, \mathrm{K}, \mathrm{Ca}, \mathrm{Ti}, \mathrm{V}, \mathrm{Cr}, \mathrm{Mn}, \mathrm{Fe}, \mathrm{Ni}, \mathrm{Zn}, \mathrm{Ga}, \mathrm{As}, \mathrm{Rb}, \mathrm{Sr}, \mathrm{Y}, \mathrm{Zr}$, and Ba. Centred log ratio (clr) was used to analyse geochemical data as an alternative to the raw percentages, following Aitchison ${ }^{104}$. Before statistical analysis, a non-parametric replacement was made for the null values below the limit of detection, according to the method proposed by Martín-Fernández et al. ${ }^{105}$. Some elements were excluded when they displayed more than one third of missing values ( $\mathrm{Cr}, \mathrm{Ni}$ and $\mathrm{Sr}$ ) or showed a heterogeneous distribution (V). We performed PCA of EDXRF concentrations for the thirteen major, minor, and trace elements more frequently detected ( $\mathrm{Si}, \mathrm{K}, \mathrm{Ca}, \mathrm{Ti}, \mathrm{Mn}, \mathrm{Fe}, \mathrm{Zn}, \mathrm{Ga}, \mathrm{As}, \mathrm{Rb}, \mathrm{Y}, \mathrm{Zr}$ and Ba). All data analyses were done with the ade 4 package ${ }^{106}$ for $\mathrm{R}$ software.

We performed XRD analyses on powder samples by using a Bruker D8 Advance diffractometer (Bragg-Brentano Theta-Theta geometry, fixed sample in the horizontal plane, movable tube and detector), goniometer diameter $600 \mathrm{~mm}$, $\mathrm{Cu}$ anti-cathode $\mathrm{X}$ source, $\mathrm{Cu}-\mathrm{K} \alpha$ incident $\mathrm{X}$ incident doublet radiation. Acquisitions were conducted with an angular range of $3-60^{\circ}$ at $2 \Theta$ (reticular distances $1.54-29 \AA$ ), measurement step $0.01^{\circ}$, with a 181 -pixel linear detector type Bruker LynxEye covering simultaneously $2.6^{\circ}$ in $2 \Theta$, an analysis time per point of $550 \mathrm{~s}$ (approximately 9 min per pixel) and an angular reproducibility of $0.017^{\circ}$, supporting sample holders of 25 -mm diameter and 1.5 -mm thickness, made of PolyMethyl MethAcrylate. Samples were previously ground and homogenized with an agate mortar. The time of analysis was $5 \mathrm{~h}$. Mineralogical phases and semiquantitative analysis were achieved by using the routine DIFFRAC.SUITE EVA software package (Bruker AXS), which allows mathematical deletion of bottom noise and the $\mathrm{Cu}-\mathrm{K} \alpha 2$ component, combined with the specific powder diffraction file (PDF2) database (International Centre for Diffraction Data-ICDD).

Reddish micro-agglomerates associated with the child's remains. The reddish micro-agglomerates, possibly fragments of iron-rich rocks commonly called ochre, were detected in the sediment coating the child's remains during their excavation and consolidation at the CENIEH. An analytical pipeline involving observation and sampling under low-magnification optical microscope, Raman spectroscopy, X-ray diffraction (XRD) and SEM-EDS, was applied to 
establish the elemental and mineralogical composition of these micro-agglomerates. The aim was to investigate whether ochre may have been involved in the mortuary practices that led to the deposition and preservation of the remains. All analyses were conducted at the CENIEH Archaeometry and Microscopy laboratories.

Two groups of reddish micro-agglomerates were analysed. The first set consisted of 55 micro-agglomerates contained in samples of reddish-brown clay sediment collected close to the maxillary, the face, and inside the cranial vault. The micro-agglomerates typically correspond to about $900 \times 600-\mu \mathrm{m}$ associations of grains with distinct reddish shades (Supplementary Fig. G1). The second group is composed of two larger-about 2-10 mm-red fragments collected on the ribs and vertebral bodies (Supplementary Fig. G2). Fifteen agglomerates from the first group and the two comprising the second group were submitted to analytical microscopy (Raman spectroscopy, SEM-EDS) and XRD analysis (Supplementary Table G3).

A FEI Quanta 600 SEM fitted with EDS, and Oxford Instruments INCA software to interface with the EDS, was used to obtain an estimation of the bulk elemental composition of the agglomerates. Operating conditions were $15 \mathrm{kV}$ of acceleration voltage, working distance of $10 \mathrm{~mm}$, and acquisition time of $90 \mathrm{~s}$, resulting in typical dead times between 10 and $17 \%$. Unless otherwise specified, results are given as compound weight percentage, oxygen calculated by stoichiometry and normalized to $100 \%$. All SEM micrographs are low vacuum secondary electron images.

The samples were first observed at low magnification - typically in the range 100-200× - to capture the entire particle (Supplementary Fig. G3). Three representative locations were then selected to investigate the sample microstructure at 1,200x, where surface features and mineral phases were measured. Three areas were analysed at each location to estimate the average bulk chemical composition. Finally, a mapping of the matrix between crystals was conducted at 2,400x and compared to the bulk composition obtained at 1,200x (Supplementary Fig. G4). Occasionally, other magnifications were used to better investigate texture, grain morphology and their relationships with elemental composition. Analyses at high magnifications were conducted to avoid potential biases due to surface irregularities and voids. The analytical procedure was adapted from the analysis of similar mineral particles described in Pitarch Martí et al. ${ }^{107}$.

The mineralogical composition of the sample was established by XRD. Owing to the destructive nature of this technique, these analyses were not performed on agglomerates analysed by SEM-EDS and RAMAN but on residues coming from the same samples. Sediment was hand ground in an agate mortar with a pestle. The resulting powder was tapped onto silicon discs and mounted in stainless steel sample holders. Patterns were collected with a PANalytical X'Pert PRO MPD diffractometer with $\mathrm{CuK} \alpha$ radiation $(\lambda=1.5406 \AA)$ and a solid-state multichannel detector. Each sample was scanned over the 2 -theta range $5-80^{\circ}$ with a step size of 0.03 . The working tension and intensity were 45 $\mathrm{kV}$ and $40 \mathrm{~mA}$, respectively, and the time of analysis ranged from 3 to $16 \mathrm{~h}$. Semi-quantitative analysis was performed on the XRD data using the X'Pert High Score software. Owing to the small amount of material analysed, the results should be regarded as qualitative.

Raman spectra were acquired using a DRX Thermo Scientific Raman dispersive spectrometer, with a laser emitting at $780 \mathrm{~nm}$. The power radiation measured under the Olympus $\times 50$ microscope objective was about $0.5-0.8 \mathrm{~mW}$. Acquisitions of about $25 \mathrm{~s}$ and multiple additions were used. The spectrometer worked in a spectral range from 55 to 
$3,350 \mathrm{~cm}^{-1}$. The calibration of the spectrometer was done with a polystyrene standard (main band $1,000 \mathrm{~cm}^{-1}$ ). The recorded mineral spectra were contrasted against the RRUFF database library for phase identification ${ }^{108}$ as well as Julien et al. ${ }^{109}$, Bellot-Gurlet et al. ${ }^{110}$, Hanesch ${ }^{111}$ and Babay et al. ${ }^{112}$.

Area C, directly accessible through Entrance 1, was the target of the 1986 to 1989 paleontological investigations. Our 2010 to 2013 work concerned Entrance 3 and Area F, which can be accessed from Area C to Areas D and E through narrows of difficult speleological negotiation. In Area F, the upper part of the sedimentary fill was largely unconsolidated and amenable to normal, trowel-aided excavation but the lower part was heavily cemented and had to be excavated with power tools, as was also the case in the Sondagem exterior (SEx) trench opened in Entrance 3. Here, investigation of the deposit was complemented by soil micromorphological analysis of representative samples spanning the complete stratigraphic sequence. Finds were manually piece plotted against site grid and site datum. The sediment was dry sieved on-site and the residue entirely saved for subsequent wet sieving and floatation. For the sediments containing the remains of phases FB2 and FB3, the sorting of fish bones from the sieved or floated sediment has yet to be carried out; therefore, fish counts are provided for FB4 only. Following established practice in the archeology of Portuguese Mesolithic shell middens, our weight/volume shell density parameter derives from bulk samples of unconsolidated sediment. Radiocarbon dating failed because the age of the samples was beyond the method's limit of applicability. The deposit's Last Interglacial age is demonstrated by the uranium (U)-series and single-grain optically stimulated luminescence (OSL) results for stratigraphically associated speleothems and the sediments themselves. Additional details and an extensive description of the dating work are provided in the supplementary materials and methods. The analytical protocols used in the study of animal and plant remains and of stone tools followed standard practice and are also further explained in the supplementary materials.

\section{Results}

\section{Primary and intentional deposit}

The hominin remains consist of a considerable part of the basicranium, a fragment of the left hemi-mandible with a complete ramus, five teeth (right $\mathrm{M}_{1}$, right $\mathrm{M}^{1}$, left $\mathrm{dm}^{2}$ and the in situ and unerupted left $\mathrm{M}_{1}$ and left $\mathrm{M}^{1}$ ), the cervical and thoracic spine with associated ribs, the right clavicle, and the left humerus (Figs. 2, 3). In addition, there were several fragments that corresponded to the cranial, facial, pectoral, pelvic and limb areas, although anatomical identification is difficult owing to postdepositional alteration (bioerosion and recrystallization) of the bones (Extended Data Table 1, Supplementary Information E). Fragments of the left radius and ulna (in anatomical connection through a lump of sediment) and a deformed fragment of the left parietal bone were also recovered, although detached from the main block. Several unidentifiable bone fragments that were recovered in the field, before the feature was plastered, probably correspond to the crushed and severely distorted upper part of the cranial vault. The advanced postdepositional alteration of the bones prevented the preservation and/ or physical recovery of the remaining skeletal elements. Photographs taken after micromorphology sampling in 2013 show the proximal portion of the right femora inside the section (Supplementary Fig. A2) and photographs of the plan view in 2017 show the proximal end of the left femur 
(Fig. 1b). On the basis of dental development, we estimate that the child, who we named 'Mtoto' ('child' in Swahili), died at the age of 2.5-3.0 years (Supplementary Information F).

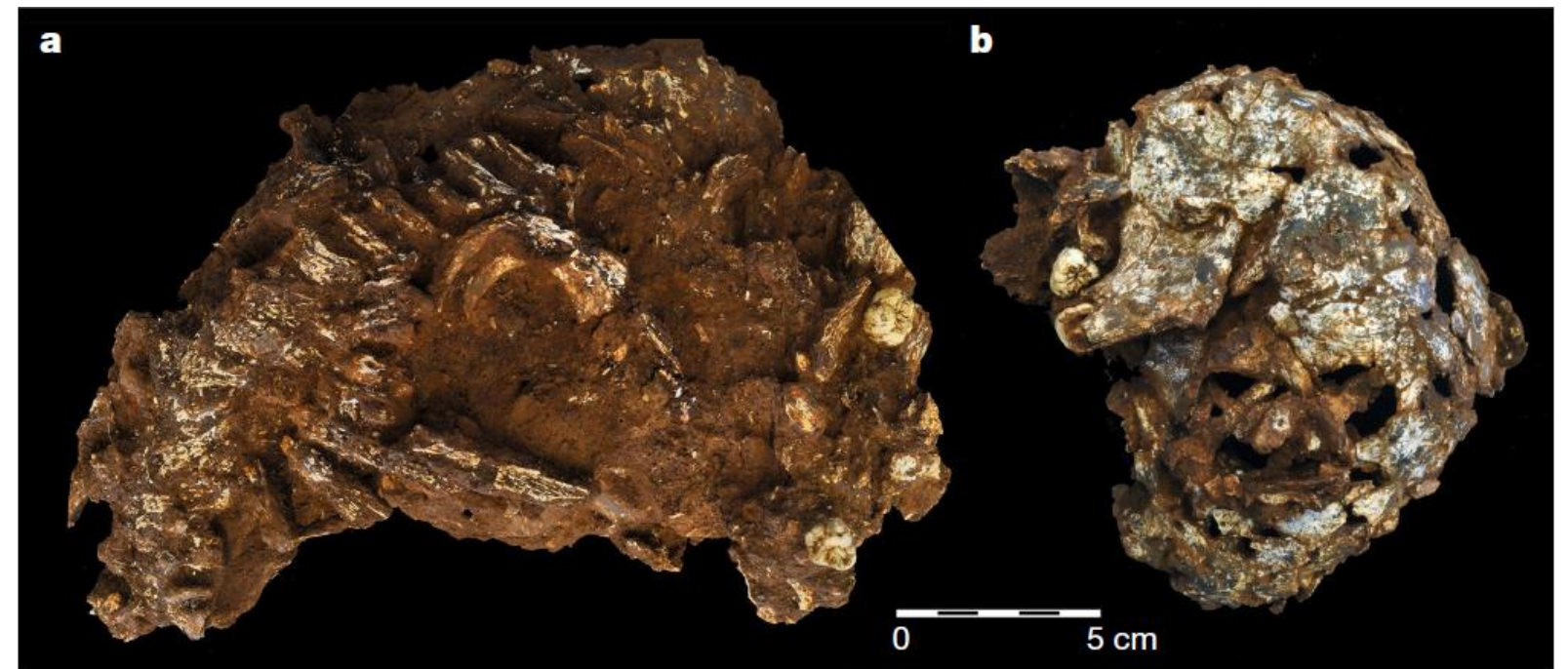

Fig. 2 I PYS human fossil. a, External view of the PYS main block, where the flexed spine with articulated vertebrae and ribs, as well as some teeth, are partially exposed on the surface. The photograph was taken after the initial cleaning and removal of three right thoracic ribs, which revealed how the first and second ribs descended and rotated into the thoracic cavity while preserving the intercostal space. This argues in favour of minimal displacement of this part of the body as a unit, given the sternal articulation of the pectoral girdle. $\mathbf{b}$, External view of the left side of Mtoto's skull and left hemimandible, showing the strict and intact temporo-mandibular articulation. The photograph was taken after the skull had been cleaned and separated from the postcranial elements. The unerupted $\mathrm{M}_{1}$ and $\mathrm{M}^{1}$ are held in place despite the fact that their roots were not developed, supporting the interpretation of an undisturbed deposit. The first three cervical vertebrae are rotated but in place, and connected to the foramen magnum.

Four features ${ }^{13}$ demonstrate that a fresh body was placed in a location where the entire process of decomposition took place: (a) the macroscopic anatomical integrity of the body, especially unstable articulations; (b) the minimal displacement of bones, with movements explained as a consequence of decompostition; (c) the abundance of terrestrial gastropods that feed on earthworms in close proximity to the corpse; and (d) geochemical and histological analyses that indicate in situ decomposition and putrefaction processes. The PYS child remains meet all four of these criteria.

The majority of the bones appear in either strict articulation or good anatomical association and minor displacements can be explained as a consequence of decomposition and the subsequent formation of secondary spaces. The combination of the photographic, surface scanner and microtomographic data, together with the total station coordinates of the pit feature, confirm that the body was deposited in a flexed right lateral decubitus position with the thighs flexed towards the torso at an angle of less than $90^{\circ}$ (Fig. 3, Extended Data Fig. 3). The vertebral column forms an arc that stretches from the cervical to the distal thoracic area. This, together with the relative position of the lower limbs, denotes a tightly flexed position of the body. The body is not lying flat, but the spine is at an angle of approximately $12^{\circ}$ above the horizontal axis. The thorax is laterally compressed. The ribs on the right side are flattened and those on the left side are at a higher angulation. There is a gap between the anterior ends of the right and the left 
ribs from the same vertebral level, consistent with the interpretation that the child's body was originally lying on its right side. Although the mechanical pressure of the sediment flattened the thorax, the rib cage did not collapse; this preserved the original spatial relationship and curvature of the ribs and points to to decomposition in a filled space. The preservation of most of the thorax articulations and thorax volume indicates that the destruction of the soft tissues and viscera did not produce a large, temporary empty space. This phenomenon tends to occur in contexts characterized by particularly fluid sediments that infiltrate by percolation, and it is indirect but solid evidence of a deposit made in bare earth $^{13}$. The particle size analysis confirms that the sediment inside the burial presents a higher proportion of both silt and sand and a lower proportion of clay in comparison to layers 17-19 (except for two samples from top of layer 18) (Extended Data Fig. 4, Supplementary Information G). This would favour progressive infilling of the internal space as the cadaver decomposed and reinforces the hypothesis that the cadaver decomposed in situ.
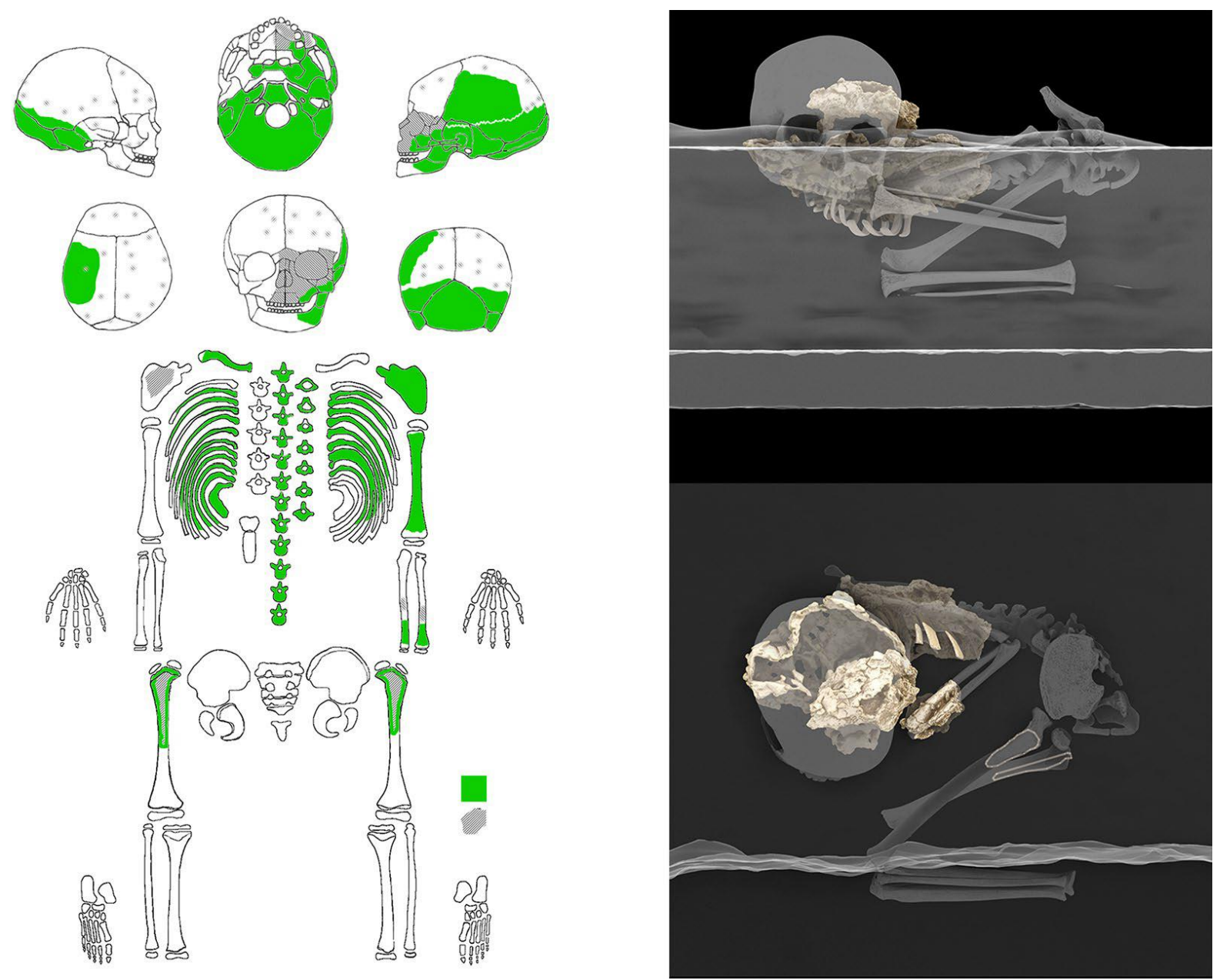

Fig. 3 | Mtoto's preservation and position in the pit. a, Preserved parts of the PYS skeleton. b, c, Front (b) and top (c) views of the virtual reconstruction of the preserved skeletal parts (solid) superimposed over a transparent comparative skeleton. The fragments of both the left and right femora could not be recovered, but their outline was identified on the plan view and in the wall profile, marked as a solid line over the transparent skeleton. The position of the right radius and ulna fragments and the right parietal bone are approximate, as they were found detached from the original block. 
The right clavicle is oriented obliquely, with the sternal extremity descending almost $90^{\circ}$. Similarly, the first and second right ribs are also distally displaced, and rotated medially by about $90^{\circ}$, but they preserve the intercostal space, arguing in favour of minimal displacement of the sternal articulation of the pectoral girdle. The depression of the clavicle and the adoption of an oblique orientation are typical of tightly shrouded burial ${ }^{14}$. This is consistent with the upper part of the body being wrapped in a perishable cloth or material, or the body being densely packed within its pit structure. In either case, such a deliberate treatment of the body would explain the exceptional in-place preservation of the scapula and humerus of the overhanging arm, and the intact articulation of the vertebral column and ribs, which would otherwise have been likely to collapse as the decomposition advanced ${ }^{13}$.

Rotation of the head is common in burials as the result of gravity and decay, where the weight of the cranium shifts away from the cranio-vertebral attachments, placing it in an unstable position. For Mtoto, the cranium and the first three cervical vertebrae are disarticulated as a unit and partially dislocated from the column. The movement of the head points to the existence of some empty space around it and contrasts with the progressive infilling and minimal displacement of the rest of the body. In a fresh cadaver, this type of head dislocation involving the cervical vertebrae could indicate collapse due to the decay of a perishable support placed beneath the head ${ }^{15,16}$. Mtoto's head dislocation, together with the depression of the clavicle and the first two ribs, is consistent with the upper part of the body being wrapped and the head supported with a perishable material. The differential preservation of the upper versus the lower part of the body could be additional evidence for this protective treatment. This evidence supports the idea that there was more elaborated involvement of the community in the funerary rite, rather than structured abandonment of a corpse 5 or a happenstance burial ${ }^{17}$.

The anatomical integrity and strict articulation of some unstable articulations indicate a primary and undisturbed deposit $^{13,14}$ and that the child was covered with sediment rapidly after its placement. Taphonomical, histological and geochemical analyses support in situ decomposition and putrefaction. The anatomical alignment and advanced diagenesis of Mtoto contrasts with the highly fragmented status and more variable diagenetic conditions of faunal remains from layers 17-19 (Extended Data Table 1, Supplementary Information H). All available evidence argues in favour of rapid burial after death, protecting the skeleton from the intense post-depositional breakage that was experienced by the faunal remains in the surrounding layers.

Optical microscopy of Mtoto's upper limb bone fragments demonstrates that human and non-human bone followed different taphonomic trajectories. The most parsimonious interpretation of the bioerosion, recystallization and Fe oxide deposition pattern on the human bone, and of the micromorphological characteristics of the burial sediment matrix, is that the child's body decomposed as a buried fleshed cadaver, in an episodically waterlogged burial environment (Supplementary Information E). The skull presents several star-shaped marks and bore holes that are indicative of insect and gastropod activity, compatible with in situ decomposition ${ }^{18}$ (Supplementary Fig. H2).

Higher concentrations of $\mathrm{MnO}$ and $\mathrm{CaO}$ in the pit fill are also consistent with in situ decomposition of the body mediated by putrefactive bacteria ${ }^{19,20}$ (Supplementary Information E, Extended Data Figs. 5, 6, Extended Data Table 2). 
The sediment matrix is devoid of microcharcoal, ash or other microscopic (putative) human inputs. Five land snail shell fragments (Achatina sp.) were found in close association with the skeleton, around the occipital area. One of these shell fragments bear lines incised by a point, not seen in fragments from the encasing layers (Extended Data Fig. 7 , Supplementary Information I). Fragments of Achatina species, however, are abundant in penecontemporaneous layer 18 and bear traces of heating and consumption. Thus, the evidence is not sufficient to suggest deliberate placement of shell fragments in the pit. Nevertheless, the Achatina shells from the pit are significantly larger than those from penecontemporaneous layer 18, indicating that they did not experience intensive breakage from processes such as trampling (Supplementary Information I). Analysis of reddish agglomerates spotted during the excavation of the child's remains showed that they were not anthropogenic in origin.

\section{Burial versus funerary caching}

In addition to the primary placement of the body, the recognition of a burial requires the identification of a purposedly excavated pit followed by intentional covering of the corpse ${ }^{5}$. The distinction of a new stratum is key to distinguishing a burial from the accommodation of a body in natural places such as cave fissures or hollows, a practice known as funerary caching 5,21 . The PYS stratigraphy provides evidence in favour of an intentional burial. The excavation of trench 4 exposed a distinct feature - a demarcated pit with sediment matrix that differed in colour and texture from the remainder of the sequence, and which can have resulted only from intentional digging into layer 19. The burial fill is a mix of ferruginous silt and sand, compositionally similar to the top of layer 18 and the base of layer 17, and different from layer 19, in which the pit was excavated (Extended Data Fig. 4, Supplementary Information G). The fine-grained texture of the intraskeletal matrix may be representative of the original composition of the burying sediment, or it may have resulted from infiltration of the sediment between the bones as the cadaver skeletonized (Supplementary Information E, Extended Data Figs. 5, 6, Extended Data Table 2). This is compatible with the evidence for progressive infilling in a deposit made in bare earth. The lack of diagnostic features of flood and/or mass flow in the burying sediment makes it unlikely that the sediment was washed into the pit during a flood event shortly after the deposition of the corpse. The most parsimonious interpretation is that Mtoto's body was deliberately covered using backfill sediment scooped from the colluvial deposits that made up the layer 18 cave floor.

In sum, the interpretation that Mtoto was intentionally buried ${ }^{5,17}$ is based on: (a) the identification of a clear pit feature dug into layer 19; (b) the geochemical and granulometric evidence that discriminates the burial fill from the surrounding layers, suggesting that sediment gradually filtered into empty spaces created by the decomposition of the body and insect activity; (c) the overall completeness and anatomical integrity of the skeleton and the alignment of the body in a tightly flexed position in the pit, consistent with rapid covering after the body's deposition; and (d) the notable difference between the unique depositionary and taphonomic history of the child's remains and that of the faunal assemblage from the same layers. 


\section{Taxonomic assessment}

We compared Mtoto's teeth against a large dental sample representative of Homo neanderthalensis and recent and fossil $H$. sapiens. Several crenulations and mesial accessory tubercles make the PYS $\mathrm{dm}^{2}$ more primitive than recent counterparts (Extended Data Fig. 8, Supplementary Information F). The PYS M $^{1}$ samples fall within the range of variation of $H$. sapiens, although they resemble the morphologically more complex Aterian individuals in their pronounced Carabelli expression and the exceptionally large and subdivided hypocones ${ }^{22}$. In both the $\mathrm{dm}^{2}$ and the $\mathrm{M}^{1}$, the occlusal polygon is more rhomboidal than in fossil and recent $H$. sapiens, but not as skewed as in Neanderthals. The size cusp sequence of the $\mathrm{M}^{1}$ falls between recent and Upper Palaeolithic H. sapiens on the one hand, and Neanderthals and Qafzeh on the other. Although the $\mathrm{M}_{1}$ morphology is compatible with that of $H$. sapiens, the profuse crenulation of their enamel makes these more complex than those of recent modern humans and some fossil H. sapiens from Africa, the Levant, Europe and East Asia ${ }^{23,24}$. The size cusp sequences in the $\mathrm{M}_{1} \mathrm{~s}$ are intermediate between that found in early H. sapiens specimens and that found in Neanderthals and recent $H$. sapiens ${ }^{25}$. The shape analysis of the occlusal outline of the enamel-dentine junction (EDJ) reveals that all PYS teeth cluster with modern humans except for $\mathrm{M}_{1}$, which is closer to Neanderthals (Extended Data Fig. 8). The dimensions of Mtoto's teeth fall within the range of variation of recent modern humans. The enamel of both deciduous and permanent molars of PYS is thick - a primitive condition shared with $H$. sapiens and the majority of speciments in the hominin fossil record except for Neanderthals (Supplementary Fig. F1).

Mtoto's dentition is consistent with an assignment to H. sapiens, although it preserves some primitive features indicating that the child was morphologically less derived than other broadly contemporaneous populations. The mandibular ramus shows a symmetric mandibular notch, where the condylar and coronoid processes are levelled. This, together with the strongly arched temporal squama, aligns Mtoto with modern humans.

\section{Implications for human cultural evolution}

Despite Africa's alleged centrality for the emergence of 'modern human behaviour' in the late Middle Pleistocene ${ }^{1,26}$, early evidence for mortuary practices in the continent is scarce. Until now, the two earliest possible burials in Africa were at Taramsa, Egypt, and Border Cave, South Africa. At Taramsa, a skeleton of a child, dated to $68.6 \pm 8 \mathrm{ka}$, was recovered in a pit similar to nearby MSA chert extraction pits ${ }^{27-29}$. As the pits relate to chert mining, Taramsa is interpreted as a late example of a long-lasting caching tradition in H. sapiens ${ }^{5}$. The infant hominin (BC3) found in 1941 at Border Cave, thought to date to approximately $74 \pm 4 \mathrm{ka}^{30}$, was apparently associated with a single perforated and ochred Conus shell. Although recent reappraisal of the evidence confirms the presence of a pit, documentation on this burial is unfortunately limited. No information is available on the degree of articulation or the position of the remains ${ }^{31,32}$ within the pit, and its age is inferred from a stratigraphic correlation with an electron spin resonance-dated section located more than $10 \mathrm{~m}$ from the pit. Although the chronological and stratigraphic data for BC3 are consistent with an age not younger than $58 \mathrm{ka}^{30}$, and possibly as old as $74 \mathrm{ka}$, a more constrained chronology for the skeleton is not available. 
The contextual, chronological and taphonomic information available at PYS are supportive of a primary burial and meet the criteria for simple, early inhumations of hominins in the Late Pleistocenes. On the basis of multiple, stratigraphically coherent OSL dates, PYS represents the earliest known evidence of an intentional burial in Africa at $78.3 \pm 4.1 \mathrm{ka}$, clearly demonstrating that complex treatment of the dead was practiced by $H$. sapiens by late marine isotope stage 5. The PYS burial reveals a clear and direct association between $H$. sapiens and MSA technology. This association is relevant in the light of current scenarios for the emergence of our species ${ }^{2,3}$, which emphasize the joint role of different African populations in this process and the possibility of regional asynchronicity in the emergence of key modern anatomical and cultural traits. The PYS child, in combination with the infant burial from Border Cave and the funerary caching of a juvenile at Taramsas, suggests that $H$. sapiens populations were intentionally preserving the corpses of young members of their groups between about 78 and $69 \mathrm{ka}$. Before $78 \mathrm{ka}$, we know of no unambiguous burials of modern humans in Africa, despite the fact that earlier MSA populations demonstrate sophisticated forms of symbolic expression ${ }^{33-36}$. Before that, intentional defleshing has been inferred for the 600,000 year-old Bodo cranium ${ }^{37}$, and the juvenile specimen from Herto ${ }^{38}$. Funerary caching has been proposed for the Atapuerca-Sima de los Huesos hominins (Spain) ${ }^{4,5}$ and H. naledi (South Africa) ${ }^{39}$.

The African evidence provides a point of contrast with Neanderthals and early modern human mortuary behaviours in Eurasia. Neanderthals and modern humans commonly buried their dead in residential sites from at least approximately $120 \mathrm{ka}^{40}$. Infant and child burials are ubiquitous in Neanderthal and early modern human sites in the Levant and Europe, comprising 55-35\% of all known Middle Palaeolithic and MSA interments after $120 \mathrm{ka}^{40}$. Burial in residential localities, such as at PYS, has been suggested to reflect mourning behaviour and the intention to keep the dead nearby ${ }^{40}$. Despite being the cradle of $\mathrm{H}$. sapiens $\mathrm{s}^{41}$, Africa demonstrates a scarcity of mortuary practices over most of the MSA that provides little current support for modern-like conceptions of the afterlife and/or treatment of the dead. Nonetheless, cross-cultural evidence in $H$. sapiens clearly emphasizes that the absence of a behaviour does not necessarily imply that the capacity for such behaviour was lacking. Evidence for advanced planning and symbolism is present by around $320 \mathrm{ka}$, and particularly after $100 \mathrm{ka}$ in eastern Africa and southern Africa ${ }^{42-44}$. The absence of burials from the onset of the MSA by around $320 \mathrm{ka}^{45}$ and the rare occurrence of burials after 78 ka may be due to a variety of factors, including cultural practices that leave elusive archaeological traces or a shift, sometime between $150 \mathrm{ka}$ and 80 $\mathrm{ka}$, from defleshing and curation ${ }^{38}$ to funerary caching and burials, observed at more recent sites in eastern Africa. The PYS burial shows that inhumation of the dead is a practice shared by populations living in and out of Africa during the last interglacial period.

The approximately 78.3-ka-old PYS skeletal remains are of interest for the insight they provide about the evolution of our species in Africa. Although the mandibular and dental assessment of Mtoto are consistent with its assignment to H. sapiens, the preservation of some primitive dental features in comparison to other penecontemporaneous populations suggests that our species may have evolved in subdivided and regionally distinct populations and in a variety of palaeoecological settings (Supplementary Information J). Our study reaffirms the suggestion that the biological and socio-cultural evolution of $H$. sapiens was a complex and regionally diverse process. 
Acknowledgements Funding for this project was provided by the SEALINKS project under a European Research Council (ERC) grant (no. 206148) and the Max Planck Society (to N.B.). Funding for the hominin analyses was from the Dirección General de Investigación of the Ministerio de Ciencia, Innovación y Universidades, grant numbers PGC2018-093925-B-C31 and C33 (MCI/AEI/FEDER, UE) and The Leakey Foundation, through the personal support of G. Getty (2013) and D. Crook (2014-2020) to M.M.-T.; analyses were also carried out at the laboratories of the CENIEH-ICTS with the support of the CENIEH staff. E.S. has a Ramón Areces/ Atapuerca Foundation postdoctoral grant. L.M.-F. is a beneficiary of an Atapuerca Foundation postdoctoral grant. S.J.A. and F.d'E. acknowledge support from the Research Council of Norway, through its Centres of Excellence funding scheme, SFF Centre for Early Sapiens Behaviour (SapienCE) (no. 262618). F.d'E. was funded by the ERC grant TRACSYMBOLS (no. 249587), the Agence Nationale de la Recherche (ANR-10-LABX-52), LaScArBx Cluster of Excellence, and the Talents programme of the University of Bordeaux, Initiative d'Excellence. A.P.M. was funded by the Beatriu de Pinós postdoctoral programme (2017 BP-A 00046) of the Government of Catalonia's Secretariat for Universities \& Research of the Ministry of Economy and Knowledge. We thank B. Kimeu for the extraction of Mtoto in the field, N. Blegen for conducting the digital work in the field, R. Blasco for insights about taphonomy, R. García and P. Saladié for assisting in anatomical identification, S. Sarmiento for the tooth photographs and M. O'Reilly for assisting with graphic design. We thank G. Musuko and family for permission to excavate the site. Permission to conduct the research was granted by the National Commission for Science, Technology and Innovation Office of the President of the Republic of Kenya through affiliation with the National Museums of Kenya (NMK). We are grateful for the support of the NMK administration, staff from the preparation and archaeology section, and the British Institute in Eastern Africa.

Author contributions N.B., M.D.P. and E.N. designed and directed the PYS research; C.S. and J.B. directed the field excavations; M.M.-T., J.M.B.d.C., J.L.A., E.S. and L.M.-F. analysed the hominin fossil; P.F.-C. conducted the mechanical restoration and conservation of the hominin; E.S. and J.G.G. conducted the virtual restoration and reconstruction of the hominin; F.d'E., N.A., W.A., S.J.A., J.B., A.C., S.D., K.D., F.-X.L.B., A.A.G., B.N., D.L., N.K., G.M., D.M., J.M., J.M.M., A.P.M., M.E.P., A.Q., S.R., P.R., M.J.S., C.S. and I.S. conducted analytical studies; M.M.T., M.D.P., F.d'E. and N.B. wrote the paper with contributions of all authors.

Competing interests The authors declare no competing interests.

\section{References}

1. Mcbrearty, S. \& Brooks, A. S. The revolution that wasn't: a new interpretation of the origin of modern human behavior. J. Hum. Evol. 39, 453-563 (2000).

2. Mounier, A. \& Mirazón Lahr, M. Deciphering African late middle Pleistocene hominin diversity and the origin of our species. Nat. Commun. 10, 3406 (2019).

3. Scerri, E. M. L. et al. Did our species evolve in subdivided populations across Africa, and why does it matter? Trends Ecol. Evol. 33, 582-594 (2018).

4. Carbonell, E. \& Mosquera, M. The emergence of a symbolic behaviour: the sepulchral pit of Sima de los Huesos, Sierra de Atapuerca, Burgos, Spain. C. R. Palevol 5, 155-160 (2006).

5. Pettitt, P. The Palaeolithic Origins of Human Burial (Routledge, 2011).

6. Zilhão, J. in Death Rituals and Social Order in the Ancient World: Death Shall Have No Dominion (eds Renfrew, C. et al.) 27-44 (Cambridge Univ. Press, 2016).

7. Roberts, P. et al. Late Pleistocene to Holocene human palaeoecology in the tropical environments of coastal eastern Africa. Palaeogeogr. Palaeoclimatol. Palaeoecol. 537, 109438 (2020).

8. Shipton, C. et al. 78,000-year-old record of Middle and Later stone age innovation in an East African tropical forest. Nat. Commun. 9 , 1832 (2018).

9. d'Errico, F. et al. Trajectories of cultural innovation from the Middle to Later Stone Age in Eastern Africa: personal ornaments, bone artifacts, and ocher from Panga ya Saidi, Kenya. J. Hum. Evol. 141, 102737 (2020).

10. Prendergast, M. E. et al. Reconstructing Asian faunal introductions to eastern Africa from multi-proxy biomolecular and archaeological datasets. PLOS ONE 12, e0182565 (2017).

11. Skoglund, P. et al. Reconstructing prehistoric African population structure. Cell 171, 59-71.e21 (2017). 
12. Grove, M. \& Blinkhorn, J. Neural networks differentiate between Middle and Later Stone Age lithic assemblages in eastern Africa. PLoS ONE 15, e0237528 (2020).

13. Duday, A. in Social Archaeology of Funerary Remains (eds Gowland, R. L. \& Knüsel, C. J.) 30-56 (Oxbow Books, 2006).

14. Knüsel, C. J. Crouching in fear: terms of engagement for funerary remains. J. Soc. Archaeol. 14, 26-58 (2014).

15. Blaizot, F. Les Espaces Funéraires de l'Habitat Groupé des Ruelles à Serris du VIle au Xle Siècles Seine et Marne, Île-de-France: Taphonomie du Squelette, Modes d'Inhumation, Organisation et Dynamique (Univ. Bordeaux, 2011).

16. Kapandii, I. A. Physiologie Articulaire: Schémas Comment Mécanique Humaine Vol. 3 (Maloine, 1972).

17. Defleur, A. Les Sépultures Moustériennes (Editions de CNRS, 1993).

18. Backwell, L., Huchet, J.-B., Jashashvili, T., Dirks, P. H. G. M. \& Berger, L. R. Termites and necrophagous insects associated with early Pleistocene (Gelasian) Australopithecus sediba at Malapa, South Africa. Palaeogeogr. Palaeoclimatol. Palaeoecol. 560, 109989 (2020).

19. Ghiorse, W. C. in Manganese in Soils and Plants (eds Graham, R. D. et al.) 75-85 (Springer, 1988).

20. Thompson, I. A., Huber, D. M., Guest, C. A. \& Schulze, D. G. Fungal manganese oxidation in a reduced soil. Environ. Microbiol. 7, 14801487 (2005).

21. Gargett, R. H. Middle Palaeolithic burial is not a dead issue: the view from Qafzeh, Saint-Césaire, Kebara, Amud, and Dederiyeh. J. Hum. Evol. 37, 27-90 (1999).

22. Bailey, S. E. \& Hublin, J.-J. in Neanderthals Revisited: New Approaches and Perspectives (eds Hublin, J.-J. et al.) 191-209 (Springer, 2006).

23. Grine, F. E. Middle Stone Age human fossils from Die Kelders Cave 1, Western Cape Province, South Africa. J. Hum. Evol. 38, 129-145 (2000).

24. Liu, W. et al. The earliest unequivocally modern humans in southern China. Nature 526, 696-699 (2015).

25. Martín-Albaladejo, M., Martinón-Torres, M., García-González, R., Arsuaga, J. L. \& Bermúdez de Castro, J. M. Morphometric analysis of Atapuerca-Sima de los Huesos lower first molars. Quat. Int. 433, 156-162 (2017).

26. Henshilwood, C. S. \& Marean, C. W. The origin of modern human behavior: critique of the models and their test implications. Curr. Anthropol. 44, 627-651 (2003).

27. Vermeersch, P. M., Paulissen, E., Gijselings, G. \& Janssen, J. Middle Palaeolithic chert exploitation pits near Qena (Upper Egypt). Paéorient 12, 61-65 (1986).

28. Van Peer, P., Vermeersch, P. M. \& Paulissen, E. Chert Quarrying, Lithic Technology and Human Burial at the Palaeolithic Site of Taramsa 1, Upper Egypt Vol. 5 (Leuven Univ. Press, 2010).

29. Vermeersch, P. M. et al. A Middle Palaeolithic burial of a modern human at Taramsa Hill, Egypt. Antiquity 72, 475-484 (1998).

30. d'Errico, F. \& Backwell, L. Earliest evidence of personal ornaments associated with burial: the Conus shells from Border Cave. J. Hum. Evol. 93, 91-108 (2016).

31. Beaumont, P. B., de Villiers, H. \& Vogel, J. C. Modern man in sub-Saharan Africa prior to 49000 years BP: a review and evaluation with particular reference to Border Cave. S. Afr. J. Sci. 74, 409-419 (1978).

32. Cooke, H. B. S., Malan, B. D. \& Wells, L. H. Fossil man in the Lebombo Mountains, South Africa: the 'Border Cave,' Ingwavuma District, Zululand. Man 45, 6-13 (1945).

34. d'Errico, F. et al. Additional evidence on the use of personal ornaments in the Middle Paleolithic of North Africa. Proc. Natl Acad. Sci. USA 106, 16051-16056 (2009).

35. Henshilwood, C. S., d'Errico, F. \& Watts, I. Engraved ochres from the Middle Stone Age levels at Blombos Cave, South Africa. J. Hum. Evol. 57, 27-47 (2009).

36. Henshilwood, C. S. et al. An abstract drawing from the 73,000-year-old levels at Blombos Cave, South Africa. Nature 562, 115-118 (2018).

37. Steele, T. E., Alvarez-Fernandez, E. \& Hallet-Desguez, E. A review of shells as personal ornamentation during the African Middle Stone Age. Paleoanthropology 24, 24-51 (2019).

38. White, T. D. Cut marks on the Bodo cranium: a case of prehistoric defleshing. Am. J. Phys. Anthropol. 69, 503-509 (1986).

39. Clark, J. D. et al. Stratigraphic, chronological and behavioural contexts of Pleistocene Homo sapiens from Middle Awash, Ethiopia. Nature 423, 747-752 (2003).

40. Dirks, P. H. G. M. et al. Geological and taphonomic evidence for deliberate body disposal by the primitive hominin species Homo naledi from the Dinaledi Chamber. elife 4, e09561 (2015).

41. Stiner, M. C. Love and death in the Stone Age: what constitutes first evidence of mortuary treatment of the human body? Biol. Theory 12, 248-261 (2017).

42. Scerri, E. M. L., Chikhi, L. \& Thomas, M. G. Beyond multiregional and simple out-of-Africa models of human evolution. Nat. Ecol. Evol. 3, 1370-1372 (2019).

43. Brooks, A. S. et al. Long-distance stone transport and pigment use in the earliest Middle Stone Age. Science 360, 90-94 (2018).

44. Henshilwood, C. S. et al. A 100,000-year-old ochre-processing workshop at Blombos Cave, South Africa. Science 334, 219-222 (2011).

45. Wadley, L. in The Oxford Handbook of African Archaeology (eds Mitchell, P. \& Lane, P.) 15 (Oxford Univ. Press, 2020).

46. Richter, D. et al. The age of the hominin fossils from Jebel Irhoud, Morocco, and the origins of the Middle Stone Age. Nature 546, 293-296 (2017). 
47. Guo, Y.-J. et al. New ages for the Upper Palaeolithic site of Xibaimaying in the Nihewan Basin, northern China: implications for small-tool and microblade industries in north-east Asia during Marine Isotope Stages 2 and 3. J. Quat. Sci. 32, 540-552 (2017).

48. Li, B., Jacobs, Z. \& Roberts, R. G. Validation of the $L_{n} T_{n}$ method for $D_{e}$ determination in optical dating of K-feldspar and quartz. Quat. Geochronol. 58, 101066 (2020).

49. Blegen, N. et al. Distal tephras of the eastern Lake Victoria basin, equatorial East Africa: correlations, chronology and a context for early modern humans. Quat. Sci. Rev. 122, 89-111 (2015).

50. Bronk Ramsey, C. Bayesian analysis of radiocarbon dates. Radiocarbon 51, 337-360 (2009).

51. Dabney, J. et al. Complete mitochondrial genome sequence of a Middle Pleistocene cave bear reconstructed from ultrashort DNA fragments. Proc. Natl Acad. Sci. USA 110, 15758-15763 (2013).

52. Rohland, N., Glocke, I., Aximu-Petri, A. \& Meyer, M. Extraction of highly degraded DNA from ancient bones, teeth and sediments for highthroughput sequencing. Nat. Protocols 13, 2447-2461 (2018).

53. Gansauge, M.-T. et al. Single-stranded DNA library preparation from highly degraded DNA using T4 DNA ligase. Nucleic Acids Res. 45 , e79 (2017).

54. Kircher, M., Sawyer, S. \& Meyer, M. Double indexing overcomes inaccuracies in multiplex sequencing on the Illumina platform. Nucleic Acids Res. 40, e3 (2012).

55. Korlević, P. et al. Reducing microbial and human contamination in DNA extractions from ancient bones and teeth. Biotechniques 59 , 87-93 (2015).

56. Glocke, I. \& Meyer, M. Extending the spectrum of DNA sequences retrieved from ancient bones and teeth. Genome Res. 27, 1230-1237 (2017).

57. Slon, V. et al. Mammalian mitochondrial capture, a tool for rapid screening of DNA preservation in faunal and undiagnostic remains, and its application to Middle Pleistocene specimens from Qesem Cave (Israel). Quat. Int. 398, 210-218 (2016).

60. Renaud, G., Stenzel, U. \& Kelso, J. leeHom: adaptor trimming and merging for Illumina sequencing reads. Nucleic Acids Res. 42 , e141 (2014).

61. Altschul, S. F., Gish, W., Miller, W., Myers, E. W. \& Lipman, D. J. Basic local alignment search tool. J. Mol. Biol. 215, 403-410 (1990).

79. Martinón-Torres, M. et al. Dental evidence on the hominin dispersals during the Pleistocene. Proc. Natl Acad. Sci. USA 104, 13279-13282 (2007).

Martinón-Torres, M. et al. Dental remains from Dmanisi (Republic of Georgia): morphological analysis and comparative study. J. Hum. Evol. 55, 249-273 (2008).

81. Martínez de Pinillos, M., Martinón-Torres, M., Martín-Francés, L., Arsuaga, J. L. \& Bermúdez de Castro, J. M. Comparative analysis of the trigonid crests patterns in Homo antecessor molars at the enamel and dentine surfaces. Quat. Int. 433, 189-198 (2017). 
82. Martinón-Torres, M., Bermúdez de Castro, J. M., Gómez-Robles, A., Prado-Simón, L. \& Arsuaga, J. L. Morphological description and comparison of the dental remains from Atapuerca-Sima de los Huesos site (Spain). J. Hum. Evol. 62, 7-58 (2012).

83. Molnar, S. Human tooth wear, tooth function and cultural variability. Am. J. Phys. Anthropol. 34, 175-189 (1971).

84. Lefèvre, J. Etude odontologique des hommes de Muge. Bull. Mem. Soc. Anthropol. Paris 10, 301-333 (1973).

85. Bermúdez de Castro, J. M., Sarmiento, S., Cunha, E., Rosas, A. \& Bastir, M. Dental size variation in the Atapuerca-SH Middle Pleistocene hominids. J. Hum. Evol. 41, 195-209 (2001).

86. Bailey, S. E. A morphometric analysis of maxillary molar crowns of Middle-Late Pleistocene hominins. J. Hum. Evol. 47, 183-198 (2004).

87. Olejniczak, A. J. et al. Dental tissue proportions and enamel thickness in Neandertal and modern human molars. J. Hum. Evol. 55, 12-23 (2008).

88. Martin, L. Significance of enamel thickness in hominoid evolution. Nature 314, 260-263 (1985).

89. Kono, R. T. Molar enamel thickness and distribution patterns in extant great apes and humans: new insights based on a 3-dimensional whole crown perspective. Anthropol. Sci. 112, 121-146 (2004).

90. Toussaint, M. et al. The Neandertal lower right deciduous second molar from Trou de l'Abîme at Couvin, Belgium. J. Hum. Evol. 58, 56-67 (2010).

91. Zanolli, C. et al. Is the deciduous/permanent molar enamel thickness ratio a taxon-specific indicator in extant and extinct hominids? $C$. $R$. Palevol 16, 702-714 (2017).

92. Olejniczak, A. J. \& Grine, F. E. High-resolution measurement of Neandertal tooth enamel thickness by microfocal computed-tomography. S. Afr. J. Sci. 101, 219-220 (2005).

93. Maureille, B., Rougier, H., Houët, F. \& Vandermeersch, B. Les dents inférieures du Néandertalien Regourdou 1 (site de Regourdou, commune de Montignac, Dordogne): analyses métriques et comparatives. Paleo 13, 183-200 (2001).

94. Scolan, H., Santos, F., Tillier, A.-M., Maureille, B. \& Quintard, A. Des nouveaus vestiges Néanderthaliens à Las Pélénos (Monsempron-Libos, Lot-et-Garonne, France). Bull. Mem. Soc. Anthropol. Paris 24, 69-95 (2012).

95. Bayle, P. et al. in Pleistocene Databases: Acquisition, Storing, Sharing (eds. Macchiarelli, R. \& Weniger, G. C.) 29-46 (Mettmann: Wissenschaftliche Schriften des Neanderthal Museums 4, 2011).

96. Macchiarelli, R., Bondioli, L., Mazurier, A. \& Zanolli, C. in Technique and Application in Dental Anthropology (eds. Irish, J. D. \& Nelson, G. C.) 425-448 (Cambridge Univ. Press, 2008).

97. Mitteroecker, P. \& Bookstein, F. Linear discrimination, ordination, and the visualization of selection gradients in modern morphometrics. Evol. Biol. 38, 100-114 (2011).

98. Bookstein, F. Morphometric Tools for Landmark Data Geometric and Biology (Cambridge Univ. Press, 1991).

99. Mitteroecker, P., Gunz, P., Windhager, S. \& Schaefer, K. A brief review of shape, form, and allometry in geometric morphometrics, with applications to human facial morphology. Hystrix 24, 59-66 (2013).

100. ISO. Particle Size Analysis — Laser Diffraction Methods https://www.iso.org/obp/ ui/\#iso:std:iso:13320:ed-1:v2:en (ISO, 2009).

101. Jones, R. M. Particle size analysis by laser diffraction: ISO 13320, standard operating procedures, and mie theory. Am. Lab. 35, 44-47 (2003).

102. Macdonald, P. \& Du, J. Mixdist: Finite Mixture Distribution Models https://cran.r-project. org/package=mixdist (2012).

103. Konert, M. \& Vandenberghe, J. Comparison of laser grain size analysis with pipette and sieve analysis: A solution for the underestimation of the clay fraction. Sedimentology 44, 523-535 (1997).

104. Sitzia, L., Gayo, E. M. \& de Pol-Holz, R. A perched, high-elevation wetland complex in the Atacama Desert (northern Chile) and its implications for past human settlement. Quat. Res. 92, 33-52 (2019).

105. Aitchison, J. The Statistical Analysis of Compositional Data (Chapman and Hall, 1986).

106. Martín-Fernández, J. A., Barcelo-Vidal, C. \& Pawlowsky-Glahn, V. Dealing with zeros and missing values in compositional data sets using nonparametric imputation. Math. Geol. 35, 253-278 (2003).

107. Dray, S. \& Dufour, A.-B. The ade4 package: implementing the duality diagram for ecologists. J. Stat. Soft. 22, 4 (2007).

108. Pitarch Martí, A., Wei, Y., Gao, X., Chen, F. \& d'Errico, F. The earliest evidence of coloured ornaments in China: the ochred ostrich eggshell beads from Shuidonggou Locality 2. J. Anthropol. Archaeol. 48, 102-113 (2017).

109. Downs, R. T. The RRUFF project: An integrated study of the chemistry, crystallography, raman and infrared spectroscopy of minerals. Prog. Abstr. 19th Gen. Meeting Intl Mineralog. Assoc. 003-13 (2006).

110. Julien, C. M., Massot, M. \& Poinsignon, C. Lattice vibrations of manganese oxides. Part I. Periodic structures. Spectrochim. Acta A Mol. Biomol. Spectrosc. 60, 689-700 (2004).

111. Bellot-Gurlet, L. et al. Raman studies of corrosion layers formed on archaeological irons in various media. J. Nano Res. 8, 147-156 (2009).

112. Hanesch, M. Raman spectroscopy of iron oxides and (oxy) hydroxides at low laser power and possible applications in environmental magnetic studies. Geophys. 177, 941-948 (2009).

113. Babay, S., Mhiri, T. \& Toumi, M. Synthesis, structural and spectroscopic characterizations of maghemite $\gamma$-Fe2o3 prepared by one-step coprecipitation route. J. Mol. Struct. 1085, 286-293 (2015). 


\section{Relative Product Size}

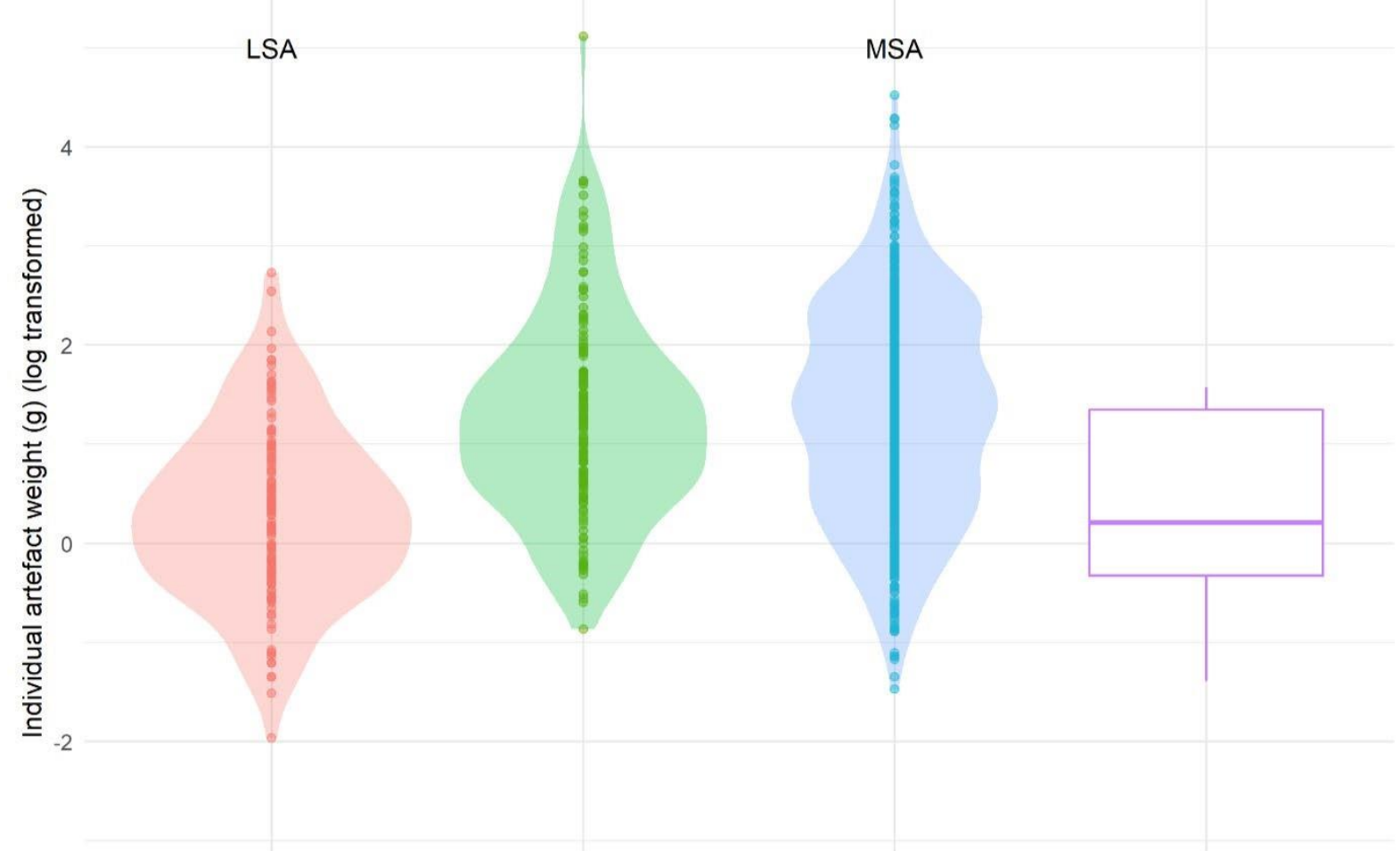

Layer $16 \quad$ Layer $17 \quad$ Layer $18 \quad$ Burial lithics $(\mathrm{n}=14)$

Stratigraphic Layer

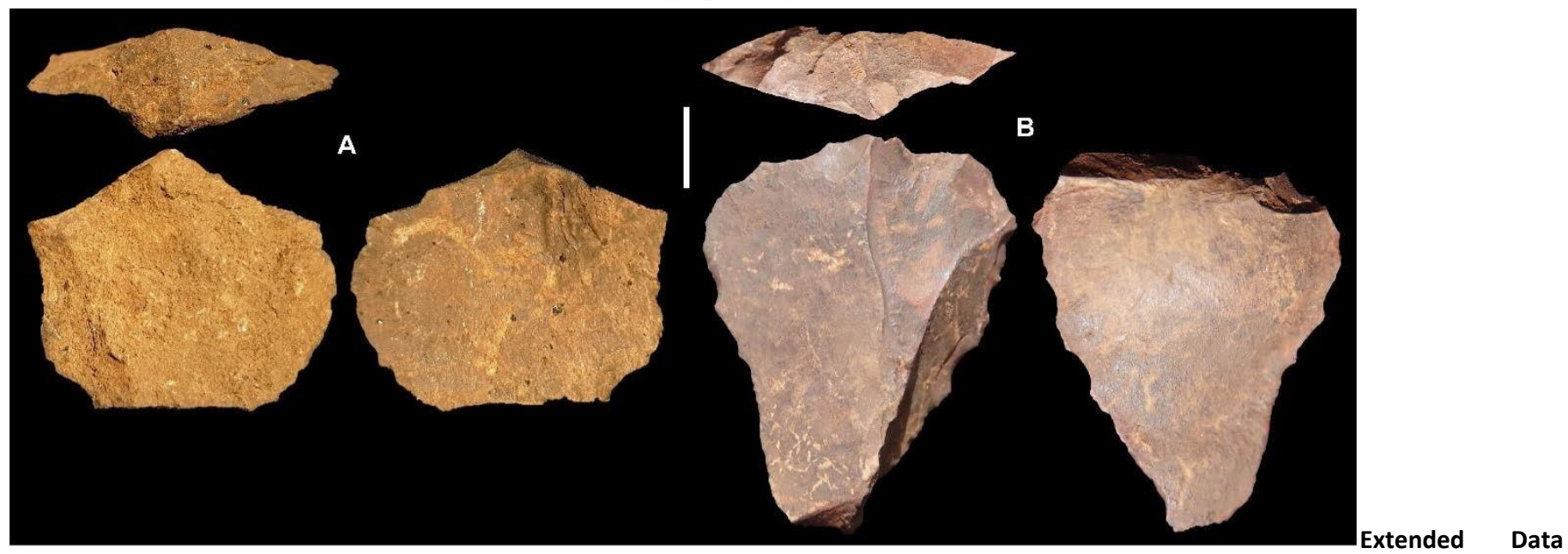

Fig. 1 | PYS MSA lithics. Top, the relative sizes of flakes through layers 18-17 (MSA) and layer 16 (early LSA) visualized with a violin plot, illustrating the density of values by layer as a continuous distribution. Note the decrease across layers $17-16$. The flakes recovered from the burial $(n=14)$, shown here with a box plot, fall within the variation in product weight for the MSA. The box plot shows the median value for burial lithics at the centre, with two neighbouring hinges marking the 25 th and 75 th percentiles. The whiskers plot the distance from the hinge values to the largest and smallest values in the burial dataset, to a maximum distance of 1.5 times the interquartile range (data beyond this range, if present, would have been plotted as individual outlier points). Below, facetted limestone flakes from MSA layers of PYS. A, limestone flake from burial context (809) with facetted dihedral platform; B, retouched limestone flake with large facetted platform from layer 17. 


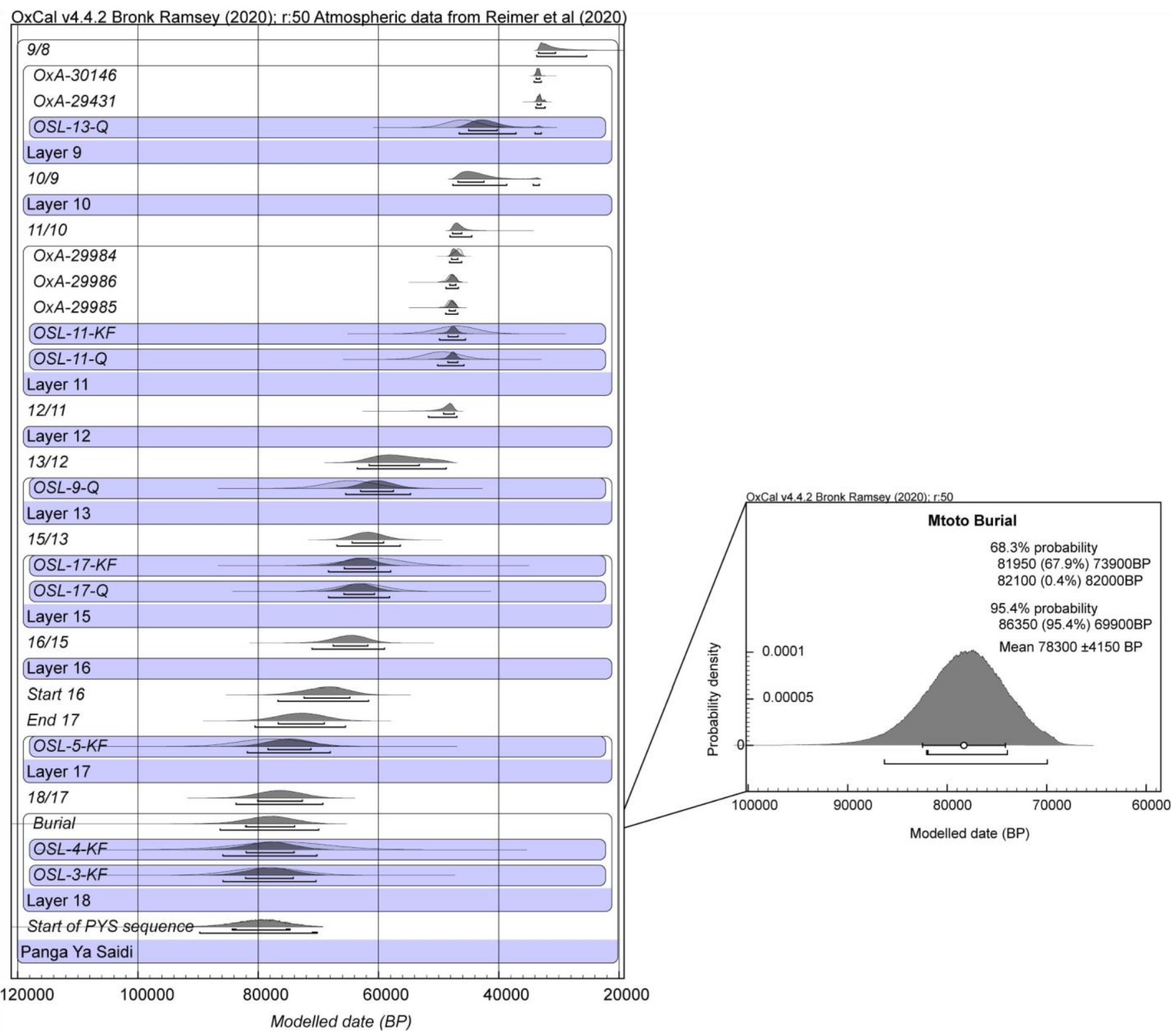

Extended Data Fig. 2 | Bayesian model for the age estimation of PYS. Left, Bayesian model of all available age determinations from PYS, produced using OxCal 4.4.2 and IntCal20. Right, age estimate of the burial determined using Bayesian model. A full description (OxCal code) of the age model is provided in Supplementary Information C. 

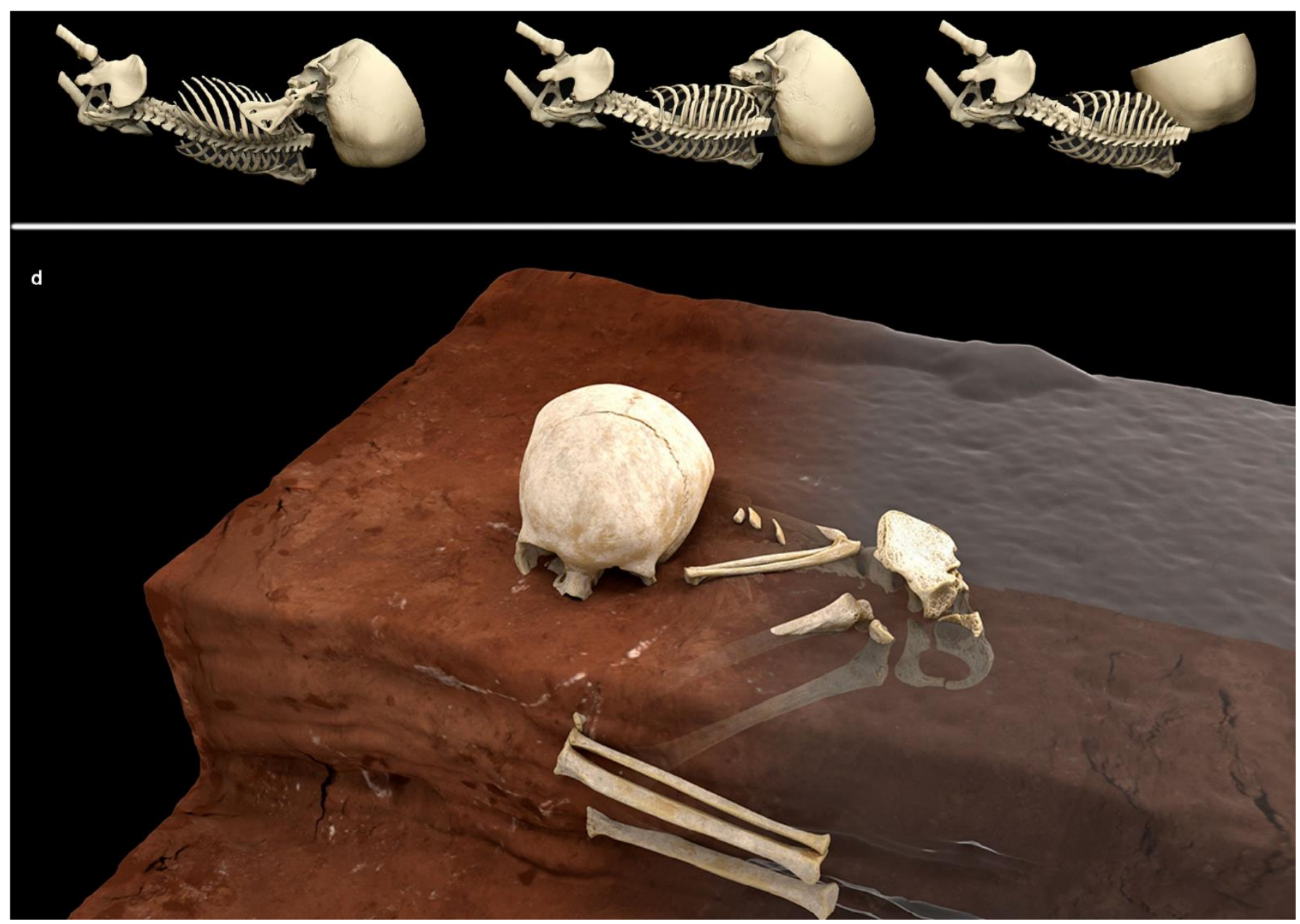

Extended Data Fig. 3 | Reconstruction of key taphonomic events of Mtoto's are flattened but the rib cage does not collapse, as is common in burial. a-c, The 3D sequence illustrates the reconstruction of the key decomposition in filled space (earth grave). c, The head dislocates, as is typical taphonomic events that affected the shape and relationship of the head and the in the case of burials with perishable head support. $\mathbf{d}$, Ideal reconstruction of spine. a, Original right lateral decubitus position of the child in the burial pit. Mtoto's original position at the moment of its discovery at the site. $\mathbf{b}$, Lateral compression of the thorax because of the sediment weight; the ribs 
a

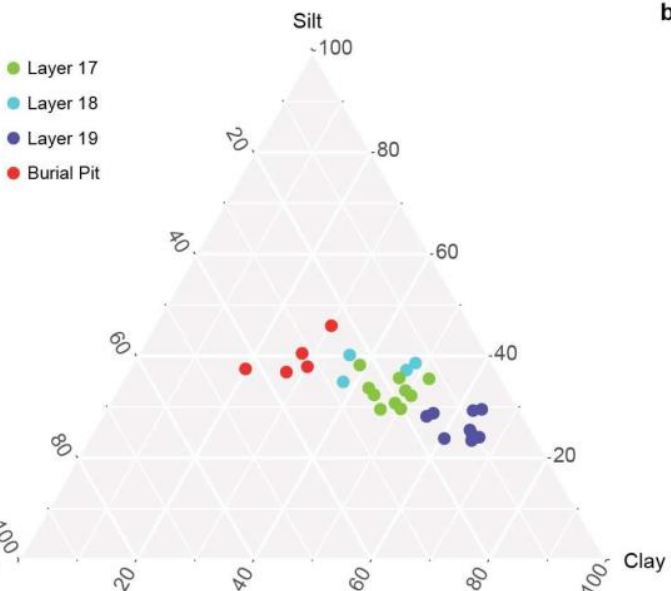

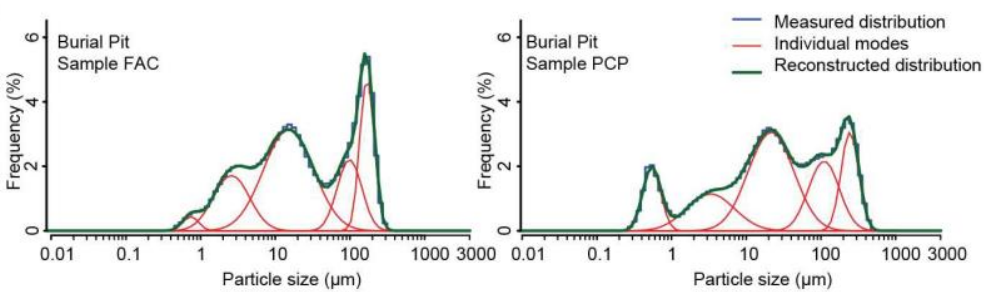
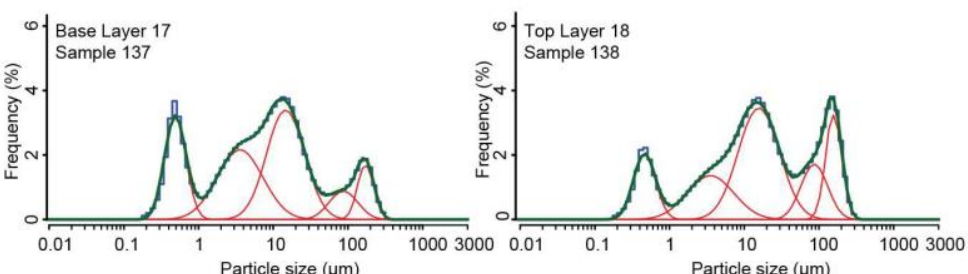

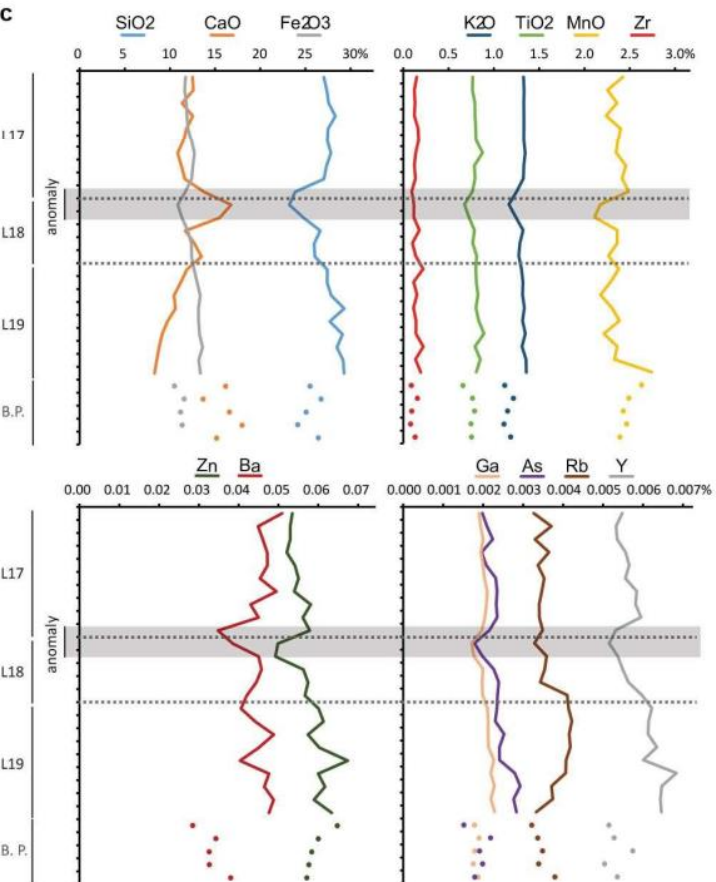

d

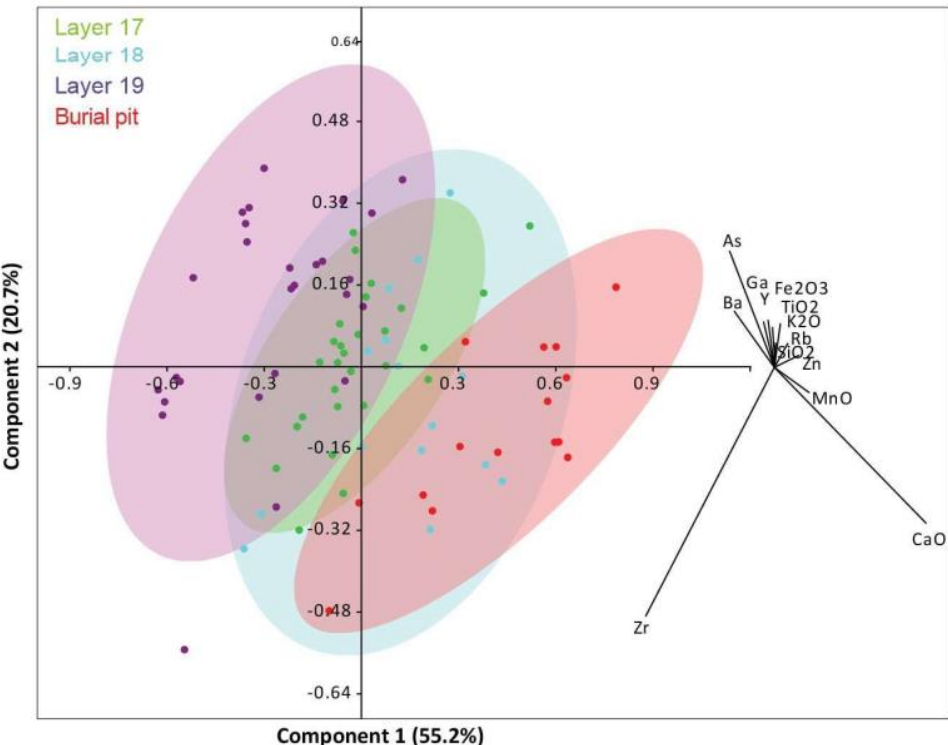

Extended Data Fig. 4 | Analysis of sediment from the stratigraphic sequence and the burial pit. a, Particle size ternary diagram indicating the higher content of sand and silt in the burial pit in comparison to the encasing archaeological layers, and in particular layer 19. b, Examples of particle size distribution and multimodal decomposition showing the similarities of sand and silt modes between the burial samples and samples 137 (base of layer 17) and 138 (top of layer 18). c, Elemental profiles of sediment from layers 17, 18, 19 and the burial pit. Element concentrations are expressed in percentages. Data are presented as mean values. Sediment samples from the burial pit display an elemental composition notably similar to the three samples identified as an anomaly at the top of layer 18 and the base of layer 17. $\mathbf{d}$, Results of PCA of the centre log ratio data (selected elements: $\mathrm{SiO}_{2}, \mathrm{~K}_{2} \mathrm{O}, \mathrm{TiO}_{2}, \mathrm{MnO}, \mathrm{Fe}_{2} \mathrm{O}_{3}, \mathrm{Zn}, \mathrm{Ga}, \mathrm{As}, \mathrm{Rb}, \mathrm{Y}, \mathrm{Zr}$ and $\mathrm{Ba}$ ). Confidence ellipses at $95 \%$. The burial pit samples markedly differ from layer 19 

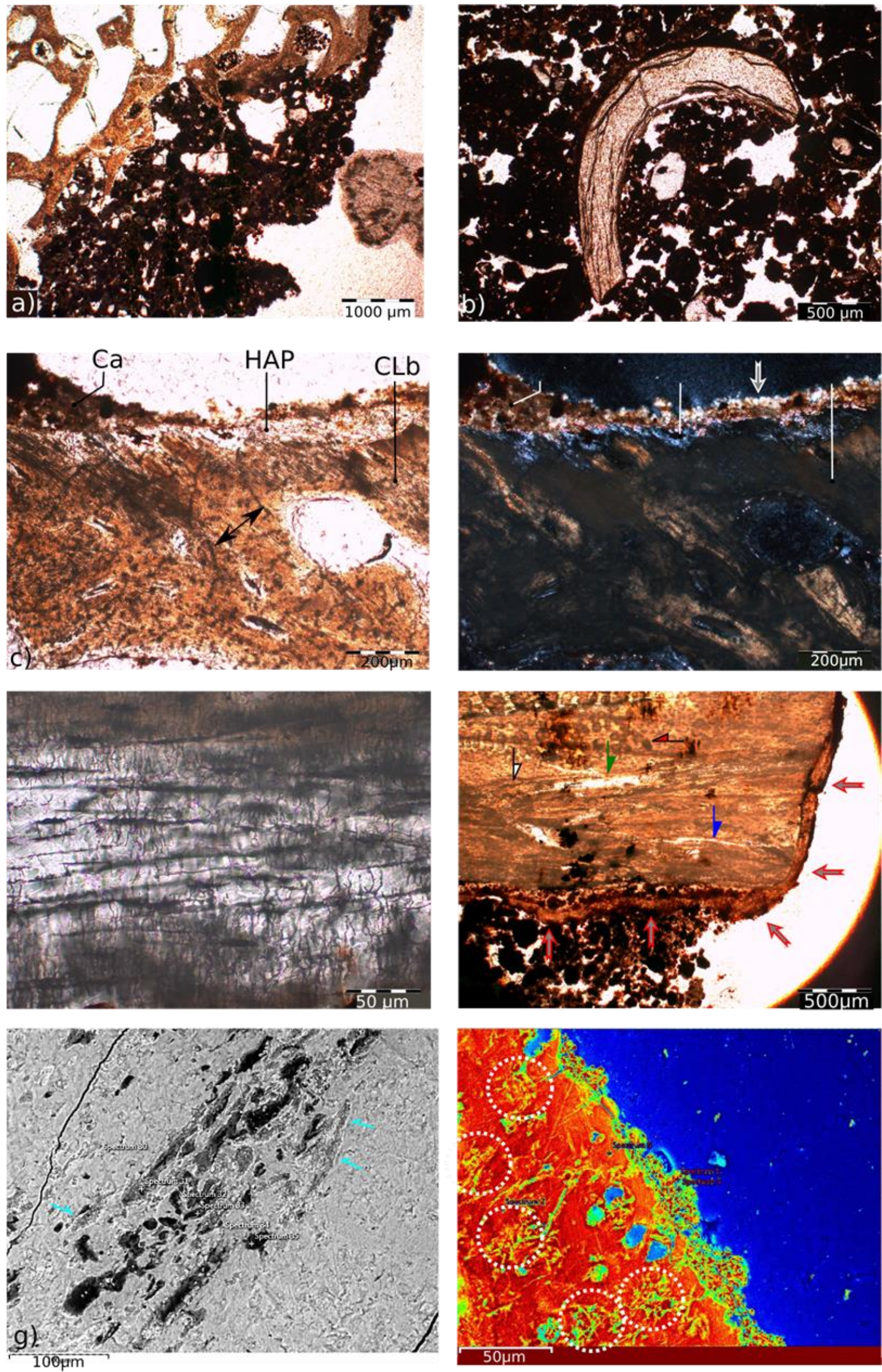
Extended Data Fig. 5 | Micromorphological and histological analysis. a-h, Polarizing microscopy (a, c-f) and SEM (g, h) images of bone and sediment from Mtoto's burial and from surrounding contexts (b). a, Ferruginous microfacies (MF-fer: here a coarser-grained variant) adhering on cancellous bone (PPL). b, Small vertebrate bone fragment from ferruginous sediment at the top of layer 18 , about $20 \mathrm{~cm}$ above Mtoto's skeleton. Note the good histological preservation and longitudinal and transverse fracturing (PPL). c, Mtoto's bone fragment. A Feoxide-stained calcite crust ( $\mathrm{Ca}$ ) covers the bone surface. A thin zone of non-clouded bone (HAP-conventionally 'hydroxyapatite') immediately beneath the bone surface is underlain with clouded, Ca-enriched bone of the mesosteum (CLb). Note the sharp boundary between HAP and CLb (especially on the left side), and the dense non-Wedl bioerosion foci within CLb (linear longitudinal tunnels at about $45^{\circ}$; budding tunnels (dark spots), attributed to bacteria) and enlarged osteocyte lacunae (smaller dark spots). Double arrow shows two possible Wedl tunnels (PPL). $\mathbf{d}$, As in c, but in XPL. The calcitic crust (Ca) comprises two layers: an Fe-oxidestained, microcrystalline layer, and a latter layer of clear, coarsercrystalline calcite (grey arrow). Birefringent areas within CLb mark osteons. Note the loss of birefringence in bioerosion foci (for example, lower right corner). e, Enlarged osteocyte canaliculi and lacunae, possibly due to fungal or fungal and bacterial action, in clouded, Ca-enriched bone (PPL). f, Advanced alteration of putative human bone (general histological index: 2), with small areas of preserved histology, pervasive clouding, fissuring (for example, blue arrow), dissolution pores (for example, green arrow) and Fe and Mn impregnation (black spots). Note the spatial patterning of bioerosion, with domains of larger, circular, coalescent non-Wedl (bacterial) MFD (for example, red arrow) and smaller, more typical tunnels (budding and linear longitudinal: for example, white arrow). A crust of calcite speleothem (grey arrows) encrusts a transverse fracture across the bone (PPL). $\mathbf{g}$, Budding and linear longitudinal tunnels in highly altered bone (area marked with white arrow in f). Some smaller-scale, spongiform bioerosion is also shown, surrounded with permineralized rims (white) of redeposited 'hydroxyapatite' (light blue arrows) (SEM image). $\mathbf{h}$, Periosteum of clouded bone $(\mathrm{Cb})$, encrusted with carbonate deposits (MF-carb). Larger circular-elliptical pores (blue/turquoise) are Haversian canals. Dashed circles show foci of fine-scale (0.1-1 $\mu \mathrm{m}$ ) bacterial bioerosion within clouded bone (SEM image, with colour temperature filter to enhance resolution). 


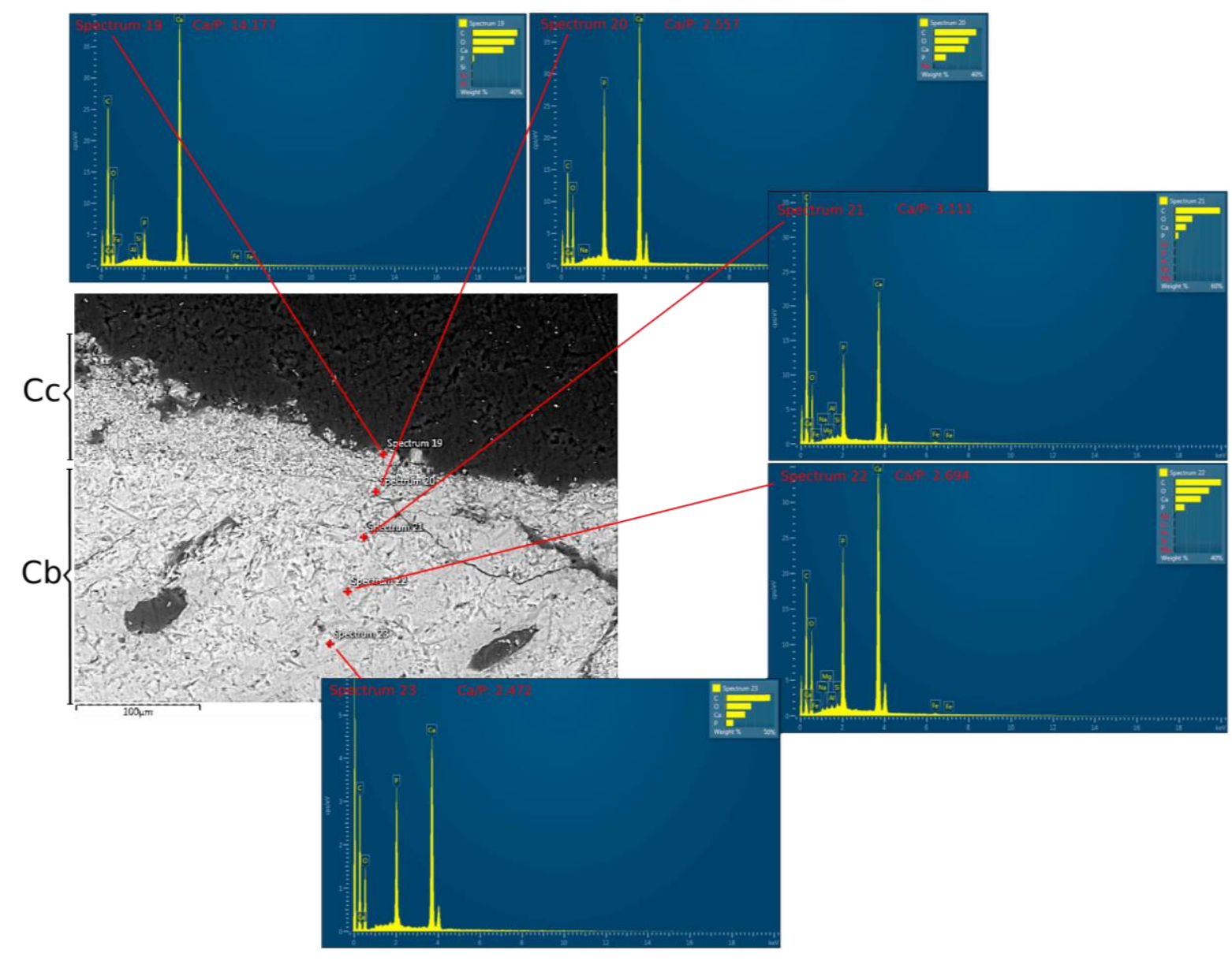

Extended Data Fig.

6 | Histological analysis of Mtoto's bone. Elemental composition of clouded bone (Cb) and encrusting calcium carbonate precipitate (Cc) (SEMEDS image and spectra). The pictured area corresponds to that of Fig. 3c, d. Diffuse lighter grey areas within the clouded bone may be permineralized rims around fine-scale $(0.1-1 \mu \mathrm{m})$ bioerosion foci. Note the variable enrichment in Ca (especially in spectrum 21$)$ and the low concentrations of $\mathrm{Fe}, \mathrm{Al}$, and $\mathrm{Mg}$ in the authigenic $\mathrm{Ca}-\mathrm{P}$ phase that makes up the clouded bone. The pervasive recrystallization of the bone hydroxyapatite into a Ca-enriched, amorphous or cryptocrystalline calcium phosphate appears to be associated with fine-scale bacterial microtunnelling. 

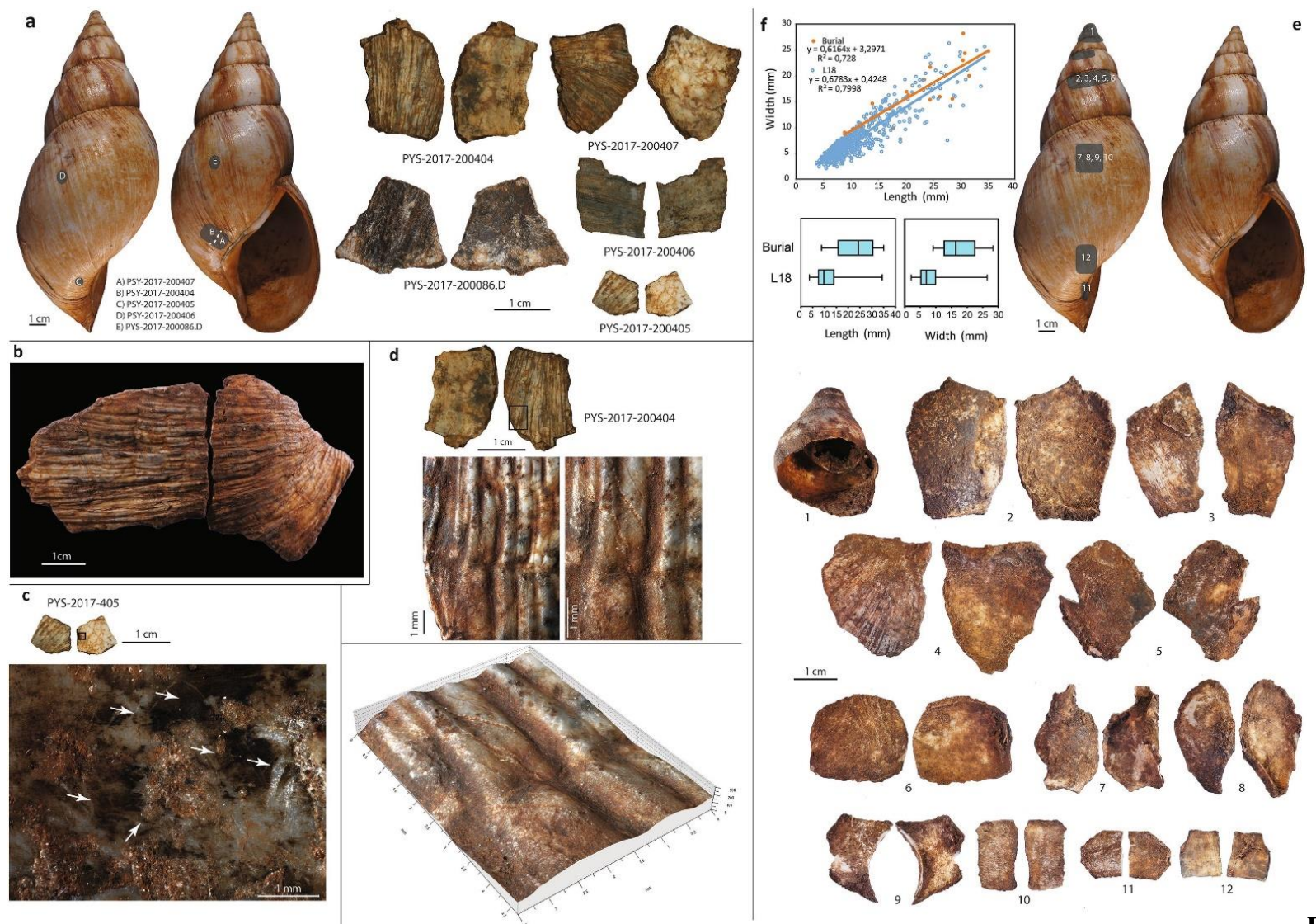

Extended Data

Fig. 7 | PYS shell analysis. a, Fragments of Achatina cf. fulica found in close association with the child's skeleton. Observation of anatomical features allows precise identification of the provenance of the fragments on the shell. Fragments PYS-2017-200407 and PYS-2017-200404 come from the area of the body whorl adjacent to the middle portion of the parietal callus. Fragment PYS-2017-200405 must come from a portion of the shell close to that of the previous fragment and may derive from the same individual. Fragment PYS-2017-200406 comes from the middle of the body whorl, on its dorsal aspect. Although anatomically it is compatible with provenance from the same individual, its very dark colour, suggestive of a higher Mn intake, and different texture of the concretion coating its outer surface indicate that it had a different taphonomic history and may derive from a different shell. Fragment PYS-2017-200086.D comes from the middle of the body whorl, on its ventral aspect. b, Refitting of fragments PYS-2017-200407 and PYS-2017-200404. The two large fragments refit along an ancient fracture perpendicularly intercepting the shell growth lines. c, Modern striations on the inner surface of specimen PYS-2017-200406, probably produced during excavation or cleaning of the fragments. The modern origin of the striations is shown by their random orientation and absence of the thin manganese patina adhering to the inner surface of this specimen. d, Micrographs and 3D reconstruction of an area of the outer surface of fragment PYS-2017-200404 showing two grooves obliquely crossing the decussated sculpture of the outer shell surface. The internal morphology and outlines of the grooves indicate that they were made by a pointed agent, possibly a stone tool, following the irregular morphology of the shell natural surface and slightly changing direction when falling into concave areas. The antiquity of the lines is demonstrated by the red sediment coating the specimen, which fills in the striations and almost completely buries them when they run into natural grooves of the shell. e, Fragments of Achatina cf. fulica found in feature 809 (bottom) and their anatomical origin (top). The twelve fragments mostly come from body whorls and last whorls of the spire of Achatina snails, with only two from the parietal wall and the apex. They present a similar state of preservation, colour, taphonomic modifications and type of concretions to the five fragments found in direct association with the skeleton. None of them bears incisions similar to those recorded on specimen PYS2017200404. Fragments comprising the control sample from layer 18 are, in general, more free from concretions than those from the skeleton and feature 809. f, Biplot and linear regression correlating the length and width of Achatina cf. fulica fragments from the grave pit $(n=12)$ and the skeleton $(n=5)$ with those from layer $18(n=581)$ (top), and box plots of length and width distributions of Achatina cf. fulica fragments from these two contexts (bottom). Rectangles in the box plots show the second and third quartiles, central bar indicates the median, and whiskers the extreme values. The fragments from the burial pit are significantly larger in size $(P=0.001)$ while displaying the same length/width ratio. Incorporation in the grave infilling have preserved Achatina fragments from the higher levels of fragmentation that have affected fragments exposed to trampling on the occupation surface in layer 18. 
A
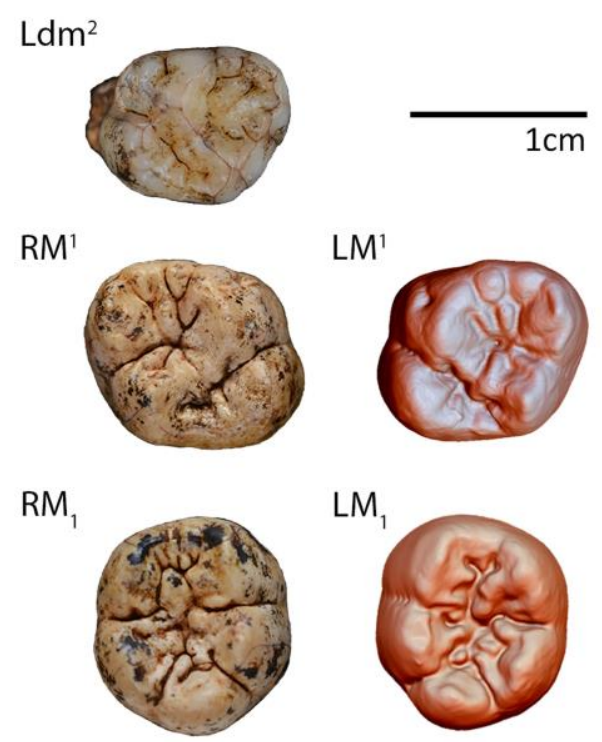

C

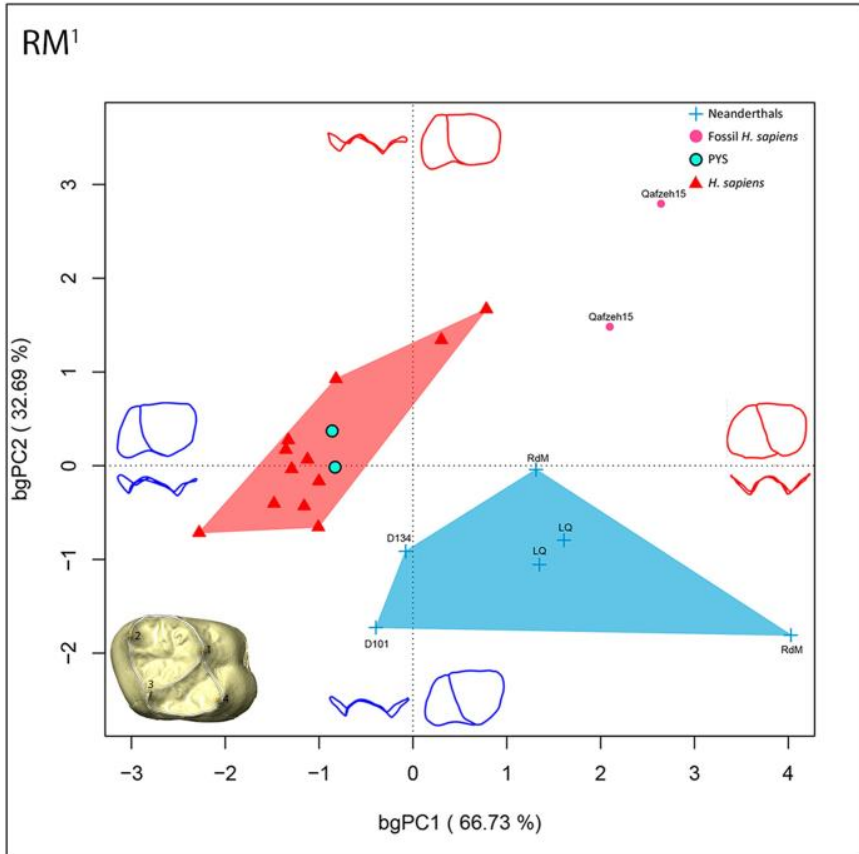

B

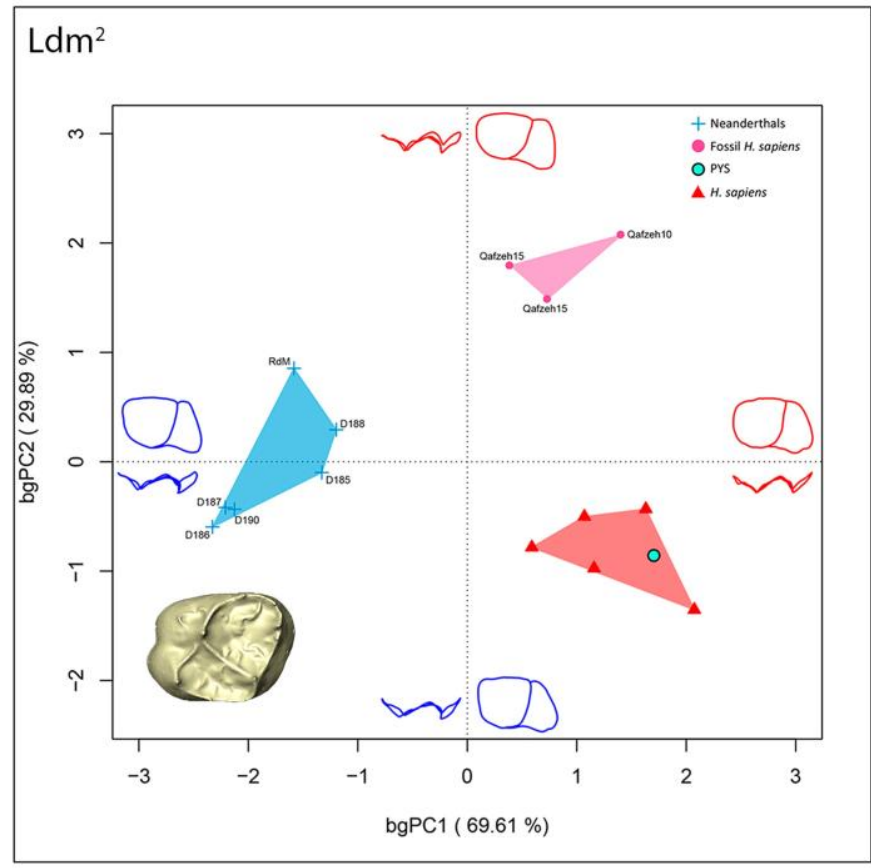

D

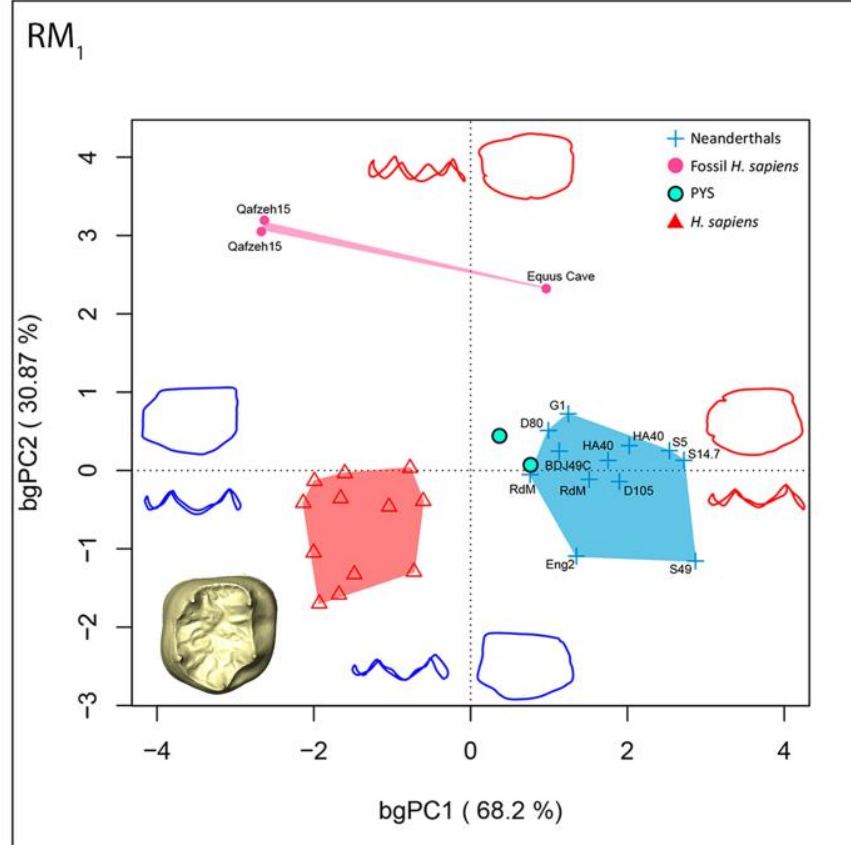

Extended Data Fig. 8 | PYS human dental remains. a, PYS dental remains: isolated teeth (left) and mCT 3D reconstruction of the two molars included in the maxillary and mandibular bones (right). All molars are positioned with the mesial surface towards the top and the distal surface towards the bottom. L (left); R (right); dm2 (second deciduous molar), $\mathrm{M}^{1}$ (permanent upper first molar), $\mathrm{M}_{1}$ (permanent lower first molar). b, bgPCA of the Procrustes shape coordinates of the PYS Ldm2 EDJ compared with those of Neanderthals $(n=6)$, fossil $H$. sapiens $(n=3)$ and modern humans $(n=5)$. c, bgPCA of the Procrustes shape coordinates of the PYS RM1 EDJ compared with those of Neanderthals $(n=6)$, fossil H. sapiens $(n=2)$ and modern humans $(n=12)$. d, bgPCA of the Procrustes shape coordinates of the PYS RM1 EDJ compared with those of Neanderthals $(n=12)$, fossil H. sapiens $(n=3)$ and modern humans $(n=12)$. 


\section{Extended Data Table 1 | PYS faunal remains}

\begin{tabular}{|c|c|c|c|c|c|c|c|c|c|c|c|c|c|}
\hline & \multirow{3}{*}{ NISP* } & \multirow{2}{*}{\multicolumn{4}{|c|}{ Circumference }} & \multirow{2}{*}{\multicolumn{4}{|c|}{ Length }} & \multicolumn{4}{|c|}{ Breakage } \\
\hline & & & & & & & & & & \multicolumn{2}{|c|}{ Diagenetic } & \multicolumn{2}{|c|}{ Green } \\
\hline & & I & II & III & IV & I & II & III & IV & NISP & $\%$ NISP & NISP & $\%$ NISP \\
\hline Micro/Small Mammals & 616 & 21 & 76 & 130 & 389 & 267 & 313 & 27 & 9 & 616 & 100 & - & - \\
\hline Intermediate-sized Mammals & 128 & 115 & 11 & 2 & - & 121 & 5 & 2 & - & 124 & 96.9 & 4 & 3.1 \\
\hline Large Mammals & 17 & 16 & 1 & - & - & 17 & - & - & - & 12 & 70.6 & 5 & 29.4 \\
\hline
\end{tabular}

Fragmentation of the appendicular skeletal elements recorded from the fill close to the burial in trench 8 . The high level of fragmentation of the faunal remains contrasts with the relative completeness but advanced degradation of Mtoto's skeletal remains, indicating different taphonomic histories for faunal and human remains. Fragmentation code: I, $<25 \%$; II, $>25 \%-<50 \%$; III, $>50 \%-<100 \%$; IV, $100 \%$. NISP, number of identified specimens

\section{Extended Data Table 2 | Diagenesis of identifiable and putative human bone in Mtoto's section}

HAP: hydroxyapatite; MFD: microscopical focal destruction.

\begin{tabular}{|c|c|}
\hline Observations & Implications \\
\hline $\begin{array}{l}\text { Bone with cortical and cancellous tissue - Homo sapiens } \\
\text { (juvenile) } \\
\text {-Occurrence: } 1-2 \mathrm{~cm} \text {, angular fragments, some with adhering } \\
\text { sediment (mainly MF-carb) } \\
\text {-Histology: cortical tissue with haversian systems ( } \pm \text { primary } \\
\text { osteons); cortical to cancellous in large fragments } \\
\text {-Colour: Light beige (incident light); orange yellow (PPL); } \\
\text { cloudy limpid, } 1^{\text {st }} \text { order orange-brown, } 1^{\text {tt }} \text { order grey in } \\
\text { periosteum (XPL) } \\
\text {-GHI: } 1-3 \text {; variable within the same fragment }\end{array}$ & \\
\hline $\begin{array}{l}\text { Bioerosion } \\
\text {-Few, localised distinctive MFD (principally linear- } \\
\text { longitudinal, budded): bacterial } \\
\text {-Enlarged osteocyte lacunae: some amalgamating: bacterial } \\
\text {-Type } 2 \text { Wedl tunnelling (periosteum: common; haversial } \\
\text { canals: rare): Fungal? } \\
\text {-Jugged periosteal surface: Unknown - bacterial? } \\
\text {-Superficial pitting: insects? }\end{array}$ & $\begin{array}{l}\text {-Arrested' bacterial bioerosion. Rapid defleshing? } \\
\text { Seasonal/episodic waterlogging? } \\
\text {-Early stages of bacterial bioerosion. Arrested } \\
\text {-Early stages of fungal bioerosion: fungi spread mainly from } \\
\text { the soil into the bone. } \\
\text {-Unknown. Post-skeletonisation } \\
\text {-Post-skeletonisation }\end{array}$ \\
\hline $\begin{array}{l}\text { Mineral/textural alteration } \\
\text {-Extensive 'clouding' ((Ca-enriched, amorphous/ } \\
\text { cryptocrystalline calcium phosphate)): mainly in cortical bone } \\
\text {-HAP to clear calcite in periosteum } \\
\text {-Clear calcite crystals in osteon canals, primary pores in } \\
\text { cancellous tissue } \\
\text {-Precipitation of authigenic Ca phosphate (HAP?) in fissures } \\
\text {-Fe, Mn oxide impregnation }\end{array}$ & $\begin{array}{l}\text {-Recrystallization of HAP (on bacterially bioeroded bone? } \\
<1 \mu \mathrm{m} \text { pores?); microbially mediated? } \\
\text {-HAP dissolution } \Rightarrow \text { calcite deposition from percolating pore } \\
\text { water } \\
\text {-Calcite deposition from percolating pore water. Microbially } \\
\text { mediated? } \\
\text {-Fluctuating pH/pore water chemistry } \\
\text {-Wetting/drying cycles; bacterially mediated chelation }\end{array}$ \\
\hline $\begin{array}{l}\text { Physical deformation } \\
\text {-Transverse fissuring (across lamellar grain) } \\
\text {-Radial fissuring, radiating from haversian canals }\end{array}$ & $\begin{array}{l}\text {-From sediment overload, or during sampling or processing } \\
\text {-Wetting/drying cycles }\end{array}$ \\
\hline $\begin{array}{l}\text { Cortical bone - Homo sapiens (juvenile) } \\
\text { - Occurrence: } 0.2-2 \mathrm{~cm} \text {, angular fragments, some with adhering } \\
\text { sediment (mainly MF-carb). The most frequent type of bone } \\
\text { fragments } \\
\text {-Histology: cortical tissue; lamellar bone with haversian and } \\
\text { Volkmann canals. } \\
\text {-Colour: chalky white, often with distinct beige periosteal rim } \\
\text { (incident light); clear to dark grey (PPL); } 1^{\text {st }} \text { order grey, } 1^{\text {st }} \text { order } \\
\text { orange brown, cloudy greenish, limpid (XPL). } \\
\text {-GHI: } 1-3(0-1 \text { in two fragments) }\end{array}$ & \\
\hline $\begin{array}{l}\text { Bioerosion } \\
\text {-MFD (mainly non-Wedl). Extend hard to assess due to } \\
\text { pervasive clouding } \\
\text {-Enlarged osteocyte lacunae; enlarged canaliculi (d: ca. 1-1.2 } \\
\mu \mathrm{m}) \text { : very frequent near the bone surface. Agent unknown; } \\
\text { probably fungal? } \\
\text {-Coalescent budded MFD } \\
\text {-Superficial pitting: insects? }\end{array}$ & $\begin{array}{l}\text {-Bacterial bioerosion did take place. Extend unknown- } \\
\text { perhaps variable across bones } \\
\text {-Action of soil fungi (+bacteria)? Timing unknown timing; } \\
\text { perhaps diachronous during putrefaction/skeletonisation? } \\
\text {-Bacterial bioerosion } \\
\text {-Post-skeletonisation }\end{array}$ \\
\hline $\begin{array}{l}\text { Mineral/textural alteration } \\
\text {-Extensive clouding (Ca-enriched, amorphous/cryptocrystalline } \\
\text { calcium phosphate): mainly in the bone interior, following } \\
\text { lamellar bone structure } \\
\text {-Clear calcite in dissolution pores } \\
\text {-HAP dissolution (mainly along lamellate grain) } \\
\text {-Precipitation of authigenic Ca phosphate } \\
\text {-Fe, Mn oxide impregnation (diffuse domains, spots, dendrites) } \\
\text {-Calcite speleothem encrustation on fracture (one fragment) }\end{array}$ & $\begin{array}{l}\text {-Recrystallization of HAP (on bacterially bioeroded bone? } \\
<1 \mu \mathrm{m} \text { pores?); microbially mediated? } \\
\text {-Calcite deposition from percolating pore water. Microbially } \\
\text { mediated? } \\
\text {-Fluctuating pH/pore water chemistry } \\
\text {-Fluctuating pH/pore water chemistry } \\
\text {-Wetting/drying cycles; bacterially mediated chelation } \\
\text {-Speleothem deposition post-fracturing } \Rightarrow \text { exposure on the } \\
\text { cave floor, or shallow underground? }\end{array}$ \\
\hline $\begin{array}{l}\text { Physical alteration } \\
\text {-Longitudinal fissuring (parallel to lamellar grain) } \\
\text {-Transverse fracturing. Fractures encrusted with calcite } \\
\text { speleothem (one fragment) }\end{array}$ & $\begin{array}{l}\text {-Desiccation in shallow underground? } \\
\text {-Unknown. Surface exposure or shallow underground? }\end{array}$ \\
\hline
\end{tabular}

